\title{
N-(3-oxo-acyl) homoserine lactone inhibits tumor growth independent of $\mathrm{Bcl}-2$ proteins
}

\author{
Guoping Zhao ${ }^{1,6}$, Aaron M. Neely ${ }^{1}$, Christian Schwarzer ${ }^{3}$, Huayi Lư ${ }^{4}$ Aaron G. Whitt ${ }^{1}$, \\ Nicole S. Stivers ${ }^{1}$, Joseph A. Burlison ${ }^{2}$, Carl White ${ }^{5}$, Terry E. Machen ${ }^{3}$, Chi Li $^{1}$ \\ ${ }^{1}$ Molecular Targets Program, University of Louisville, Louisville, KY 40202, USA \\ ${ }^{2}$ Structural Biology Program, James Graham Brown Cancer Center, Departments of Medicine, Pharmacology and Toxicology, \\ University of Louisville, Louisville, KY 40202, USA \\ ${ }^{3}$ Department of Molecular and Cell Biology, University of California, Berkeley, CA 94720, USA \\ ${ }^{4}$ Second Hospital of Jilin University, Changchun, Jilin Province, P.R. China 130041 \\ ${ }^{5}$ Department of Physiology and Biophysics, Rosalind Franklin University of Medicine and Science, North Chicago, IL 60064, USA \\ ${ }^{6}$ Institute of Technical Biology and Agriculture Engineering, Hefei Institutes of Physical Science, Chinese Academy of Sciences, \\ Hefei, Anhui Province, P.R. China 230031
}

Correspondence to: Chi Li, e-mail: chi.li@louisville.edu

Keywords: homoserine lactone, BCl-2, Bak, Bax, tumor

Received: July 17, $2015 \quad$ Accepted: December 22, $2015 \quad$ Published: January 07, 2016

\section{ABSTRACT}

Pseudomonas aeruginosa produces $\mathrm{N}$-(3-oxododecanoyl)-homoserine lactone (C12) as a quorum-sensing molecule for bacterial communication. C12 has also been reported to induce apoptosis in various types of tumor cells. However, the detailed molecular mechanism of C12-triggerred tumor cell apoptosis is still unclear. In addition, it is completely unknown whether $\mathrm{C} 12$ possesses any potential therapeutic effects in vivo. Our data indicate that, unlike most apoptotic inducers, $\mathrm{C12}$ evokes a novel form of apoptosis in tumor cells through inducing mitochondrial membrane permeabilization independent of both pro- and anti-apoptotic $\mathrm{Bcl}-2$ proteins. Importantly, C12 inhibits tumor growth in animals regardless of either pro- or anti-apoptotic $\mathrm{Bcl}-2$ proteins. Furthermore, opposite to conventional chemotherapeutics, $\mathrm{C} 12$ requires paraoxonase 2 (PON2) to exert its cytotoxicity on tumor cells in vitro and its inhibitory effects on tumor growth in vivo. Overall, our results demonstrate that $\mathrm{C} 12$ inhibits tumor growth independent of both pro- and anti-apoptotic $\mathrm{Bcl}-2$ proteins, and through inducing unique apoptotic signaling mediated by PON2 in tumor cells.

\section{INTRODUCTION}

Quorum sensing is a bacterial intercellular communication system that constitutively produces, releases, and detects small diffusible autoinducers that are similar to mammalian hormones [1]. The gram-negative human pathogen Pseudomonas aeruginosa uses $\mathrm{N}$-(3-oxododecanoyl)-L-homoserine lactone (C12) as a quorum sensing signal $[2,3]$.

Recent studies have shown that $\mathrm{C} 12$ is not only important in regulating bacterial virulence genes but also interacts with eukaryotic cells and modulates cell physiology, such as triggering cell death [4]. C12 has been demonstrated to cause apoptosis in a variety of cancer cells [5-8]. C12 induces apoptosis through inhibiting the phosphatidylinositide 3-kinases and Akt/ PKB pathway and diminishing STAT3 activities in breast carcinoma cells [5]. In pancreatic carcinoma cells, C12 also triggers apoptotic signaling and inhibits cell migration
[6]. C12 decreases the expression of thymidylate synthase and enhances the activity of chemotherapeutic agents, 5-fluorouracil (5- FU), Tomudex and Taxol in colorectal and prostate cancer cells. Recently, a derivative of $\mathrm{C} 12$, 3-oxo-12-phenyldodecanoyl-L-homoserine lactone, has been identified as another cancer cell growth inhibitor [8]. Comparative SAR analysis demonstrates that long acyl side chains with a 3-oxo substitution are essential for $\mathrm{C} 12$ 's anti-cancer effect [8]. In light of its function of triggering tumor cell death, $\mathrm{C} 12$ displays promise as a cancer treatment. However, detailed apoptotic signaling of $\mathrm{C} 12$ remain unclear and whether $\mathrm{C} 12$ cytotoxicity in vitro is relevant to tumor growth in vivo has never been studied.

Resistance toward apoptosis is a hallmark of most, perhaps all, types of human cancer [9, 10]. Bcl-2 proteins are the major regulators of apoptotic signaling pathways and can be classified into anti-apoptotic and pro-apoptotic groups. Anti-apoptotic Bcl-2 proteins such as $\mathrm{Bcl}-2$ are considered to protect against mitochondrial 
outer membrane permeabilization (MOMP) during apoptosis, whereas pro-apoptotic Bcl-2 members such as Bax and Bak promote MOMP [11, 12]. The expression of individual Bcl-2 proteins in different types of cancer has been used as an independent prognostic marker [10]. Studies in various human tumors showed that loss of Bax expression, or increased expression of Bcl-2, are associated with their resistance to chemotherapy [13-15]. Accordingly, one strategy for cancer therapy is to identify agonists that activate apoptotic pathway independent of $\mathrm{Bcl}-2$ proteins in tumor cells [16-18].

As a lactone, $\mathrm{C} 12$ is known to be hydrolyzed into a carboxylic acid by the lactonase paraoxonase 2 (PON2), which belongs to a gene family (PON1, PON2 and PON3) with $\mathrm{Ca}^{2+}$-dependent lactonase and arylesterase activities $[19,20]$. In murine airway epithelia, PON2 attenuates Pseudomonas aeruginosa quorum sensing by inactivating C12 [21]. PON2 and PON3 also display anti-oxidant and anti-inflammatory functions [22-24]. The detailed mechanism by which PON2 exerts these effects remains unknown. Importantly, PON2 expression is markedly elevated in several human non-small cell lung carcinoma (NSCLC) cell lines, which is associated with resistance to classical anticancer drugs like doxorubicin or cisplatin $[23,24]$. In contrast, overexpression of PON2 promotes C12-induced apoptosis in MEFs and HEK293T cells [25].

To gain insights into the mechanism of C12-evoked tumor cell apoptosis, we evaluated the cytotoxic effects of $\mathrm{C} 12$ on tumor cells in vitro and the inhibitory effects of $\mathrm{C} 12$ on tumor growth in vivo. The role of pro- and anti-apoptotic Bcl-2 and PON2 proteins in $\mathrm{C} 12$-induced apoptosis was systematically examined. C12 inhibited the tumor growth through inducing apoptosis in a PON2dependent but not Bcl-2 protein-dependent manner. Our study reveals a unique anti-tumor function of $\mathrm{C} 12$, which may lead to the development of new therapeutic agents for cancer.

\section{RESULTS}

\section{C12 inhibits lung tumor growth and induces tumor cell apoptosis in vivo}

The cytotoxic effects of $\mathrm{C} 12$ on tumor cells have been reported previously $[5-8,26]$, but whether they are selective for transformed cells was unknown. To investigate whether oncogenic transformation influences the cytotoxicity of $\mathrm{C} 12$, we studied normal human bronchia/tracheal epithelial (NHBE) and corresponding HBE immortalized and transformed successively by telomerase, SV40 large T antigen and activated Ras (H-ras V12) [27-29]. This is a well-established epithelial cell malignant transformation system related to human lung cancer. Following C12 treatment, transformed HBE exhibited higher levels of cell death (Figure 1A and Supplementary Figure 1A) and caspase-3/7 activation
(Figure 1B and Supplementary Figure 1B) compared with their untransformed counterparts, indicating that $\mathrm{C} 12$ induces apoptosis preferentially in transformed cells.

To investigate the relevance of $\mathrm{C} 12$ cytotoxicity on transformed cells to tumor growth in animals, we examined the effects of $\mathrm{C} 12$ on the growth of established Lewis Lung Carcinoma (LLC) tumors. As shown in Figure $1 \mathrm{C}$, transplanted tumors grew much more slowly in $\mathrm{C} 12$-treated mice than in vehicle-treated mice, revealing a dose-dependent anti-tumor activity of $\mathrm{C} 12$ as a single agent. No significant changes of body weight and organ weight (spleen, kidney, liver, heart and lung) were observed for C12-treated C57BL/6 mice (Supplementary Figure 2A and 2C), showing no evidence of significant toxicities of $\mathrm{C} 12$ administration. To test the involvement of apoptosis in tumor growth inhibition, established LLC tumors from mice were analyzed for caspase- 3 activation through immunofluorescence staining (Figure 1D-1E), western blot (Figure 1F-1G) and TUNEL staining (Figure 1H-1I). The percentage of TUNEL-positive cells and the levels of activated caspase- 3 were higher in tumors from $\mathrm{C} 12$-treated mice than in those of the control group, suggesting that apoptosis is involved in the inhibitory activity of $\mathrm{C} 12$ in vivo.

In order to explore the therapeutic potential of $\mathrm{C} 12$, we studied the combinatorial effects of $\mathrm{C} 12$ and therapeutic drugs. Cell death of human lung tumor cells A549 and NCI-H1299 treated with various concentrations of $\mathrm{C} 12$ and the inhibitor of Bcl-2 and Bcl- $x_{L}$ ABT-737 at a constant dose ratio were measured, and the combination index (CI) values were determined (Supplementary Figure 3). As shown in Supplementary Figure 3C and 3F, in the range of tested drug concentrations, $\mathrm{CI}$ values were smaller than 1, indicating that $\mathrm{C} 12$ and ABT-737 exhibited synergistic cytotoxic effects on A549 cells and NCI-H1299 cells.

\section{Anti-apoptotic Bcl-2 proteins does not affect $\mathrm{C} 12$ cytotoxicity}

Anti-apoptotic Bcl-2 proteins are frequently overexpressed in human cancers and associated with chemotherapeutic resistance and relapse [30]. To investigate the involvement of anti-apoptotic Bcl-2 proteins in $\mathrm{C} 12$-induced human tumor cell apoptosis, Bcl-2, Mcl-1 and Bcl- $\mathrm{x}_{\mathrm{L}}$ were stably overexpressed in A549 cells respectively by retroviral infection (Figure 2A and Supplementary Figure 4A and 4D). The anti-tumor drug actinomycin $\mathrm{D}$ caused less cell death and caspase-3/7 activation in $\mathrm{Bcl}-2-, \mathrm{Mcl}-1$ - or $\mathrm{Bcl}-\mathrm{x}_{\mathrm{L}}$-overexpressing cells than in cells expressing the empty vector (Figure 2B-2C and Supplementary Figure 4B-4C and 4E-4F). In contrast, $\mathrm{C} 12$ induced similar levels of cell death and caspase-3/7 activation in cells overexpressing Bcl-2, Mcl-1 or Bcl- $\mathrm{x}_{\mathrm{L}}$ and the vector control cells (Figure 2B-2C and Supplementary Figure $4 \mathrm{~B}-4 \mathrm{C}$ and $4 \mathrm{E}-4 \mathrm{~F}$ ). To further 
A

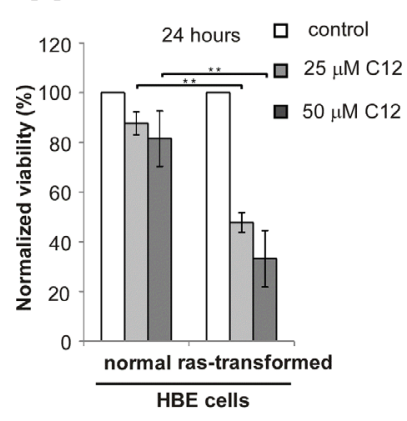

B

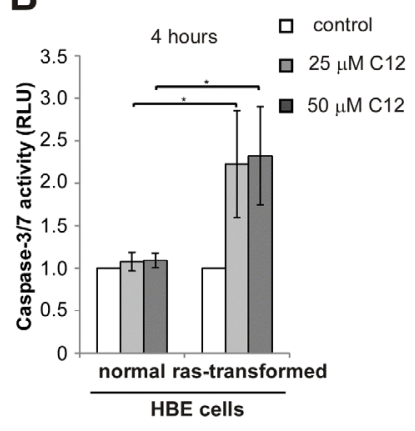

C ${ }_{40}$

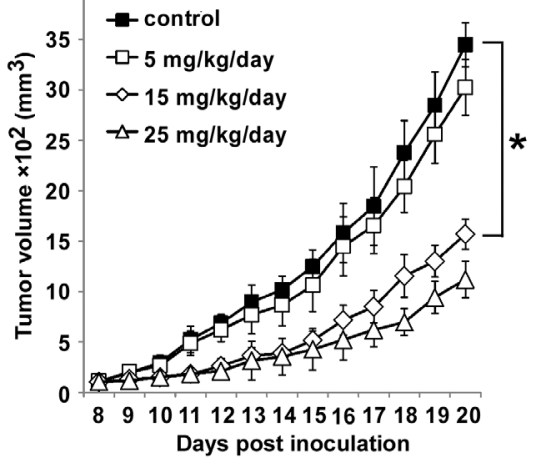

D control

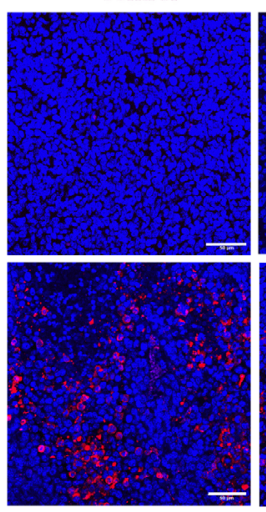

$15 \mathrm{mg} / \mathrm{kg} / \mathrm{day}$ activated caspase-3
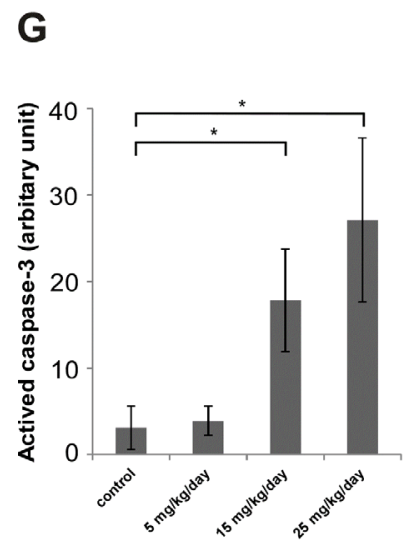

G

H
$5 \mathrm{mg} / \mathrm{kg} / \mathrm{day}$

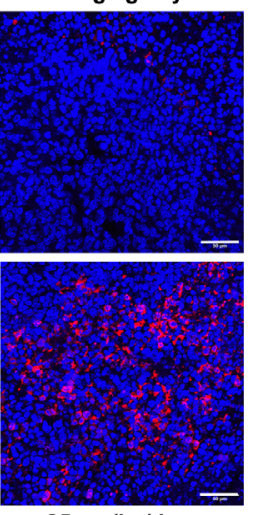

E

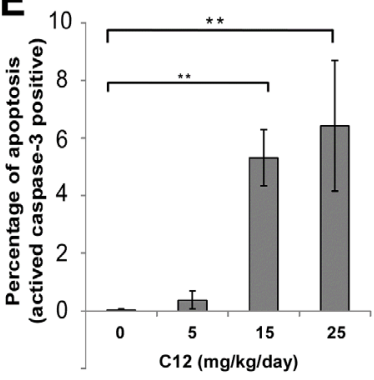

F

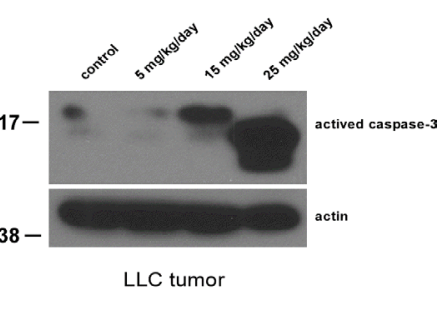

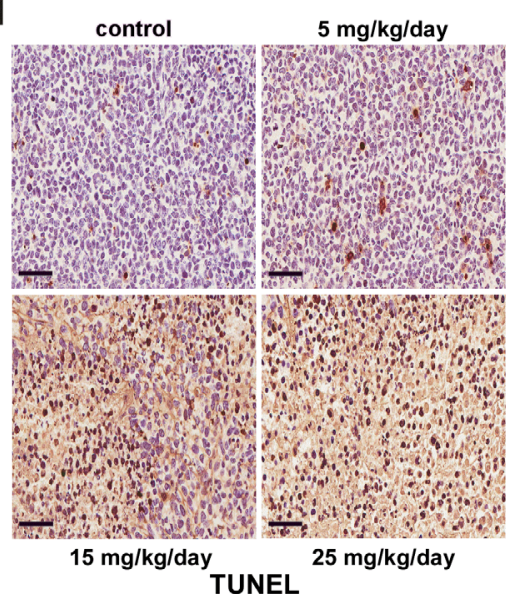

I

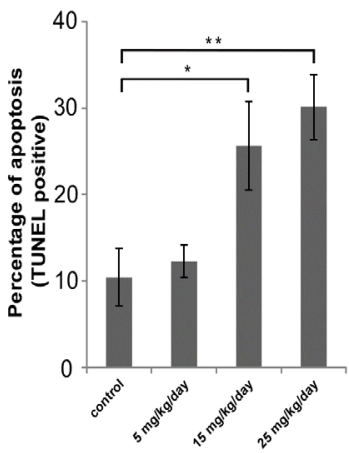

Figure 1: C12 inhibits LLC tumor growth and induces tumor cell apoptosis in vivo in a dose-dependent fashion. (A-B) Cytotoxicity of $\mathrm{C} 12$ is affected by oncogenic transformation. C12's effects on HBE cell viability (A) and caspase-3/7 activation (B) were examined. All data shown are mean \pm standard deviation of 3 independent experiments. Asterisk indicates $P<0.05(*)$ or $P<0.01(* *)$ by student's unpaired $t$ test. (C) The inhibitory effects of C12 on the growth of LLC tumors were studied. Tumors were measured daily and tumor tissues were removed at the end of treatments. Data are shown as mean \pm standard deviation of tumor volumes of 7 animals in either vehicle control or C12-treated group. Asterisk indicates $P<0.05\left(^{*}\right)$ by student's unpaired $t$ test. (D) Apoptotic cells in tumor sections were detected by immunofluorescence staining of activated caspase-3. Representative images of tumor sections are shown. Scale bar, $50 \mu \mathrm{m}$. (E) The percentage of activated caspase-3 shown in (D) was quantified using ImageJ software (NIH). Data are mean \pm standard deviation of three independent tumor sections. Asterisk indicates $P<0.01(* *)$ by student's unpaired $t$ test. (F) Expression of activated caspase-3 in tumor tissues was analyzed by western blot. (G) The relative expression levels of activated caspase-3 shown in (F) were quantified by measuring intensities of western blot signals using ImageJ software and presented as arbitrary units. Data are mean \pm standard deviation of three independent tumor samples. Asterisk indicates $P<0.05\left(^{*}\right)$ by student's unpaired $t$ test. (H) TUNEL staining of apoptotic cells in control or C12-treated tumor sections. Representative images are shown. Scale bar, $60 \mu \mathrm{m}$. (I) The percentage of apoptotic cells shown in $(\mathrm{H})$ was quantified using Image J software. Data are mean \pm standard deviation of three independent tumor sections. Asterisk indicates $P<0.05(*)$ or $P<0.01(* *)$ by student's unpaired $t$ test. 

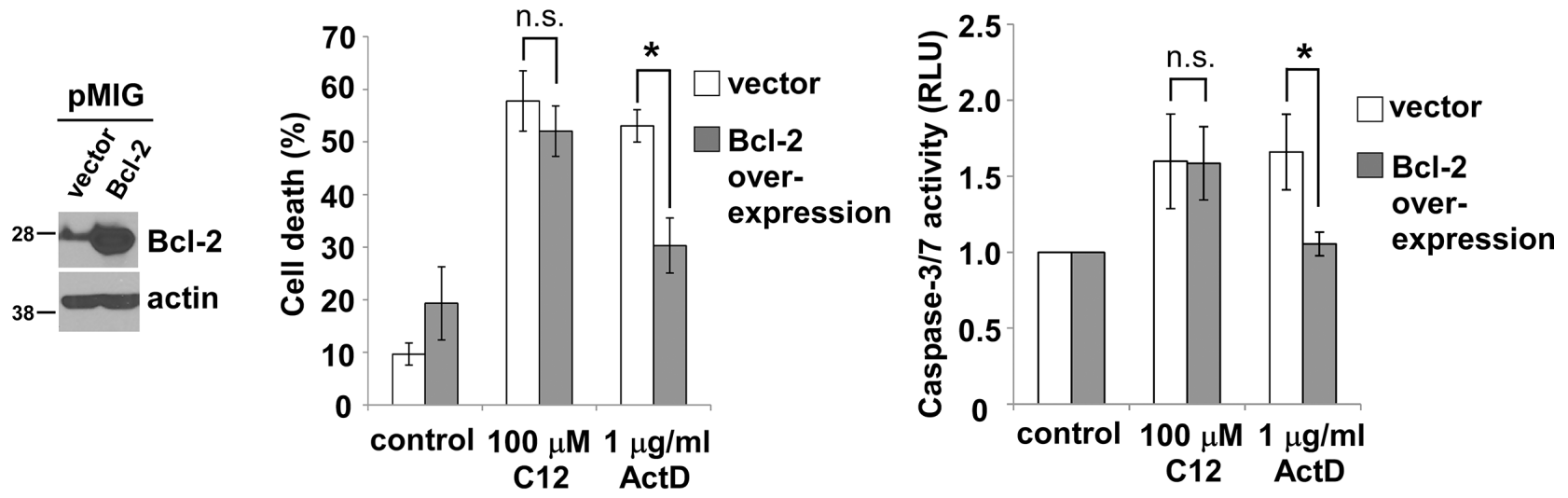

D
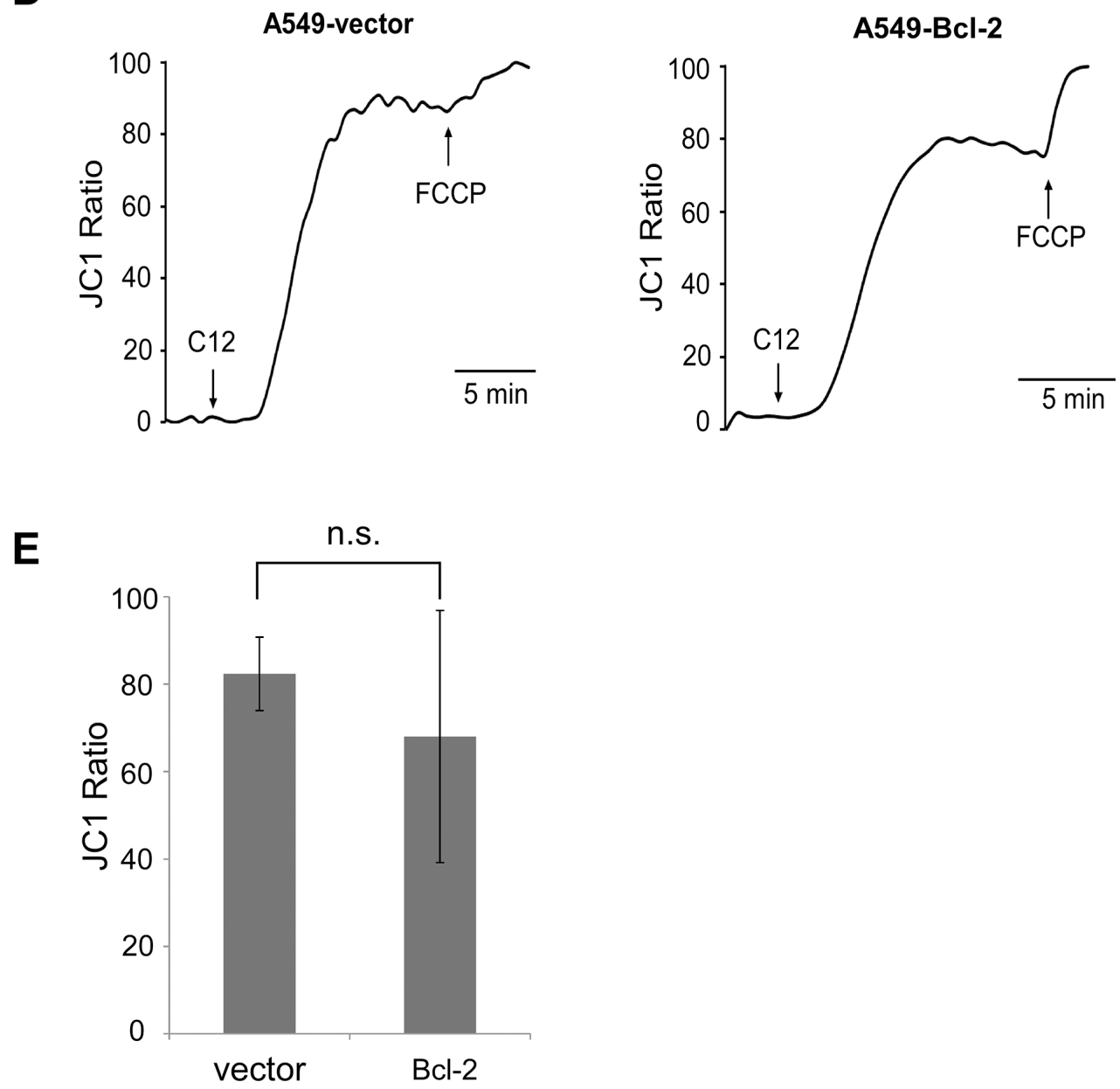

Figure 2: C12 induces tumor apoptotic cell death independent of anti-apoptotic Bcl-2 proteins. (A) Retrovirally overexpressed Bcl-2 in A549 cells was examined by western blot. (B) Cell viability was measured 48 hours after C12 or actinomycin D (ActD) exposure. (C) Caspase-3/7 activities were determined following 2 hour exposure to $\mathrm{C} 12$ and 24 hour exposure to actinomycin D. (D) C12's effect on mitochondrial membrane potential is independent of Bcl-2. A549-vector and A549-Bcl-2-overexpressing cells were loaded with JC1, and its fluorescence was measured using imaging microscopy during the treatment with $100 \mu \mathrm{M} \mathrm{C12}$ and $5 \mu \mathrm{M}$ FCCP. Typical results from three independent experiments are shown. (E) C12 caused equivalent depolarization of mitochondrial potential in vector and Bcl-2-overexpressing A549 cells. All data are shown as mean \pm standard deviation of three independent experiments. Asterisks indicate $P<0.05(*)$; ns, no significant by student's unpaired $t$ test. 
explore the involvement of Mcl-1 in mediating C12induced cytotoxicity, we examined A549 cells in which Mcl-1 expression was stably reduced by shRNA [31]. Actinomycin D but not C12 caused more cell death and caspase-3/7 activation in Mcl-1-knockdown cells than the cells expressing the control scramble shRNA (Supplementary Figure 4G-4H), further validating that Mcl-1 expression is not vital for $\mathrm{C} 12$-induced apoptotic signaling.

MOMP has been recognized to be a "no-return" step during mitochondria-based apoptotic signaling [32]. To further investigate C12-initiated apoptosis in tumor cells, we studied the involvement of Bcl-2 in two key events of MOMP: depolarization of mitochondrial membrane potential $\left(\Delta \psi_{\text {mito }}\right)$ and cytochrome c release. Depolarization of $\Delta \psi_{\text {mito }}$ was evaluated by determining the changes in fluorescence of the voltage-dependent dye $\mathrm{JC} 1$ released from mitochondria into the cytosol and nucleus. Within minutes of $\mathrm{C} 12$ exposure, mitochondria in A549-vector cells and A549-Bcl-2 overexpressing cells were depolarized to the same degree (Figure 2D-2E). While depolarizing $\Delta \psi_{\text {mito }}$ quickly, C12 did not appear to affect mitochondrial morphology with mitochondrial interconnectivity determined by mean area/ perimeter ratio and mitochondrial elongation measured by inverse circularity, indicating that mitochondrial fission/fusion is unlikely involved in the initiation of MOMP in cells exposed to C12 (Supplementary Videos 1-4 and Supplementary Figure 5). Moreover, C12 caused cytochrome c release from mitochondria in both A549- vector and Bcl-2 or Mcl-1 over-expressing A549 cells (Supplementary Figure 6A-6B). Taken together, these results indicate that overexpression of anti-apoptotic $\mathrm{Bcl}-2$ proteins reduces apoptosis in response to the classical anti-tumor drug actinomycin D but fails to provide protection against $\mathrm{C} 12$.

\section{C12 blocks tumor growth independent of Bcl-2 protein}

To determine whether anti-apoptotic Bcl-2 proteinindependent $\mathrm{C} 12$ cytotoxicity is relevant in vivo, we examined its effects on the growth of tumors originated from A549 cells with different levels of Bcl-2 expression in athymic nude mice. Similarly to C57BL/6 mice, C12 caused no significant change of body weight and organ weight (spleen, kidney, liver, heart and lung) in C12-treated athymic nude mice (Supplementary Figure 2B and 2D). As shown in Figure 3A-3B, A549-Bcl-2 overexpressing tumors grew much faster than their vector control counterparts, which is consistent with the oncogenic function of Bcl-2 [33]. C12 inhibited the growth of vector control A549 tumors and Bcl-2-overexpressing A549 tumors to a comparable degree. Inhibitory effects of C12 on tumor growth are likely attributed to apoptosis, as more TUNEL-positive cells were detected in C12-treated tumors than vehicle-treated ones regardless of Bcl-2 expression levels (Figure 3C-3D). Overall, these results show that Bcl-2 is not involved in the cytotoxic effects of $\mathrm{C} 12$ in vitro as well as in vivo.

\section{Bak and Bax are not involved in C12-induced apoptosis}

Previous studies show that $\mathrm{C} 12$ induces apoptosis in MEFs independent of Bak and Bax [25, 34], two pro-apoptotic Bcl-2 members required for MOMP in almost all apoptotic paradigms [35]. To clarify their role in $\mathrm{C} 12$-induced tumor cell apoptosis, human colon carcinoma HCT116 cell lines lacking Bak alone, Bax alone, or both Bak and Bax (Bak/Bax-DKO) were studied (Figure 4A). C12 caused roughly equivalent cell death and caspase-3/7 activation in all the HCT116 cell lines examined, indicating that deficiency of Bak and Bax in HCT116 cells did not influence their responses to C12 (Figure 4B-4C). Unlike C12, the therapeutic drug etoposide induced significant cell death and caspase-3/7 activation in wild-type (WT), Bax-KO and Bak-KO but not in Bak/Bax-DKO HCT116 cells (Supplementary Figure 7A-7B). Moreover, deficiency in Bak/Bax expression did not affect C12's effect to depolarize $\Delta \psi_{\text {mito }}$ (Figure 4D-4E) and release cytochrome c (Supplementary Figure 8), indicating $\mathrm{Bak} / \mathrm{Bax}$ are not involved in C12-induced MOMP in tumor cells. These results demonstrate that $\mathrm{C} 12$-induced apoptotic signaling is distinct from that triggered by conventional anti-cancer drugs.

\section{The inhibitory effects of C12 on tumor growth are independent of Bak and Bax}

To further investigate whether the Bak/Baxindependent effect of $\mathrm{C} 12$ to trigger apoptosis in vitro also occurred in vivo, WT and Bak/Bax-DKO HCT116 cells were inoculated into athymic nude mice. $\mathrm{C} 12$ reduced the growth of established HCT116-WT tumors and HCT116Bak/Bax-DKO tumors to a similar degree (Figure 5A-5B), indicating that Bak and Bax are not involved in antitumor activity of C12. Moreover, the level of activated caspase-3 and the percentage of TUNEL-positive cells were higher in C12-treated tumors than vehicle-treated tumors regardless of Bak and Bax expression levels (Figure 5C-5F), suggesting that $\mathrm{C} 12$ inhibits tumor growth probably through inducing Bak/Bax-independent apoptosis. Unlike C12, etoposide inhibited the growth of WT HCT116 tumors but not that of Bak/Bax-DKO HCT116 tumors (Supplementary Figure 7C-7D).

\section{BH-3 only proteins Noxa and Puma are not involved in C12-induced tumor cell apoptosis}

BH3-only proteins are another class pro-apoptotic Bcl-2 proteins, which share sequence homology only 
in the BH3 domain, including Noxa and Puma [36]. To further elucidate whether $\mathrm{BH} 3$-only proteins are involved in $\mathrm{C} 12$ cytotoxicity in tumor cells, we investigated two HCT116 cell lines in which Noxa expression was stably reduced by shRNA (Figure 6A) or Puma expression was eliminated genetically (Figure 6E) [37, 38]. C12 caused similar levels of cell death and caspase-3/7 activation in HCT116 cell lines with reduced expression of Noxa or
Puma compared with their corresponding counterparts expressing normal levels of Noxa or Puma (Figure 6B and $6 \mathrm{~F}-6 \mathrm{G})$. In contrast, less cytotoxicity was observed in HCT116 cells with decreased Noxa or Puma expression in response to conventional apoptosis stimuli (Figure 6C and $6 \mathrm{~F}-6 \mathrm{G})$. Overall, our results suggest that $\mathrm{BH} 3$-only proteins are not critical for $\mathrm{C} 12$-induced apoptotic signaling.
A

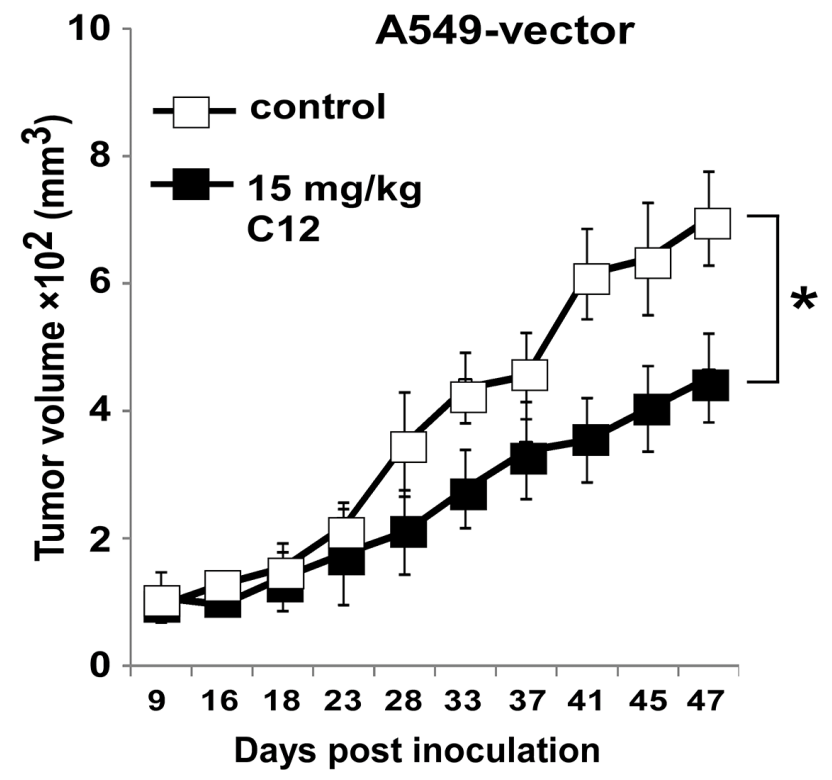

C

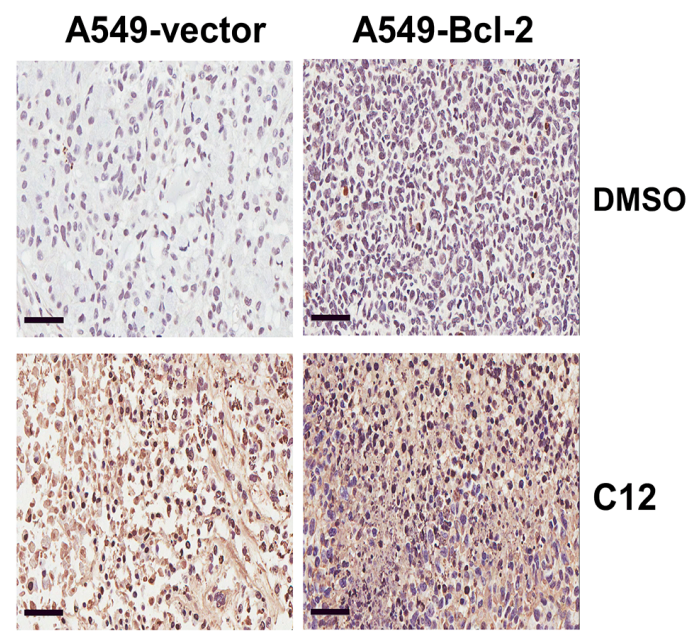

TUNEL
B

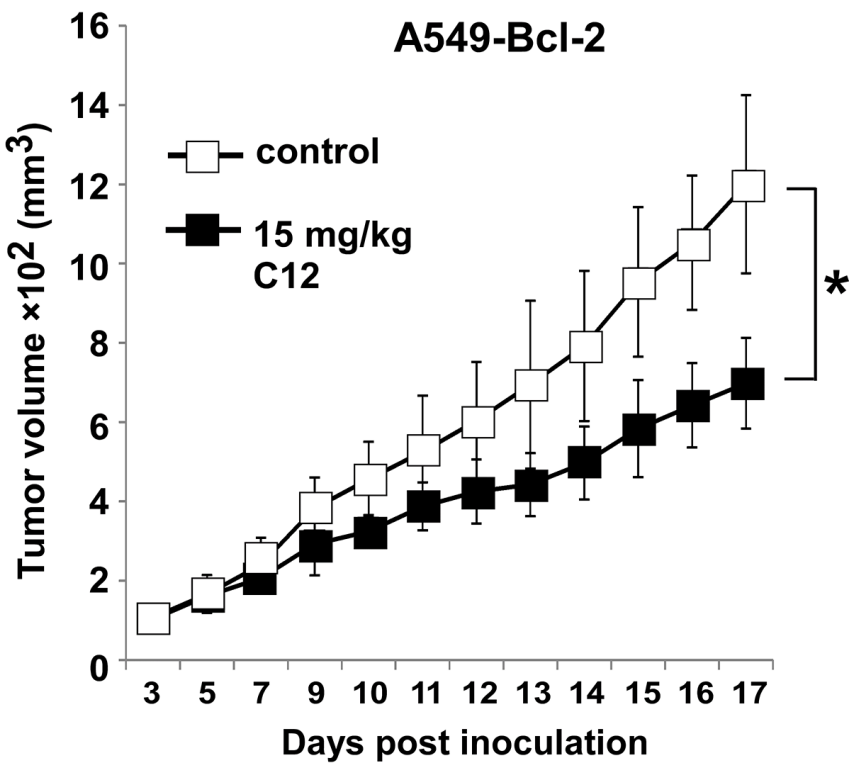

Figure 3: C12 inhibits tumor growth independent of Bcl-2. (A-B) Growth of A549-vector (A) and A549-Bcl-2-overexpressing tumors (B) in athymic nude mice treated with the vehicle control or C12 (15 mg/kg/day). Data are shown as mean \pm standard deviation of tumor volumes of 8 animals in either vehicle control (DMSO) or C12-treated groups. (C) Apoptotic cells in tumor sections were identified by TUNEL assay. Representative images of tumor sections from DMSO- and C12-treated mice are shown. Scale bar, $60 \mu \mathrm{m}$. (D) Summary of the data shown in (C). More apoptotic cells were detected in tumors of C12-treated mice than those of vehicle control mice. Mean \pm standard deviation of three independent tumor sections. For all the data, asterisk indicates $P<0.05(*)$ by student's unpaired $t$ test. 
PON2 expression was increased in human lung tumor tissues and oncogenically transformed HBE cells

It has been shown that PON2 upregulation in some cancer cells, including lung cancer cell lines, enables cancer cells to become resistant to conventional therapeutic drugs [23]. To determine whether PON2 expression is enhanced in human lung cancer, we examined PON2 protein levels in tumor tissues of non small cell lung carcinoma (NSCLC) patients by western blot (Figure 7A). Among eleven samples from patients, we found that PON2 was overexpressed in eight of lung cancer tissues compared with corresponding adjacent normal tissues, whereas its expression was slightly decreased in three of them (Figure 7B). As Ras-transformed HBE displayed higher levels of apoptosis compared with their untransformed counterparts upon $\mathrm{C} 12$ treatment (Figure 1A-1B and Supplementary Figure 1), PON2 expression was also increased in transformed HBE cells (Figure 7C), providing more evidence that oncogenic transformation enhances PON2 expression.

\section{PON2 is involved in C12's cytotoxicity on tumor cells and inhibitory effects on tumor growth}

In nontransformed MEF and HEK293T cells, overexpression of $\mathrm{PON} 2$ promotes cytotoxicity of $\mathrm{C} 12$ [25], but the role of endogenous PON2 in C12-evoked apoptotic signaling was unclear. To further investigate the mechanism of C12-triggered apoptosis, we studied the involvement of endogenous PON2 in C12 cytotoxicity

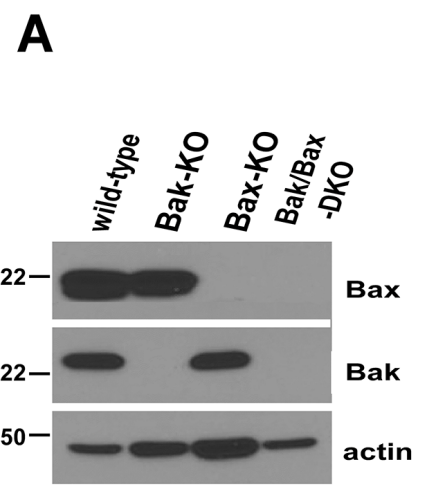

B

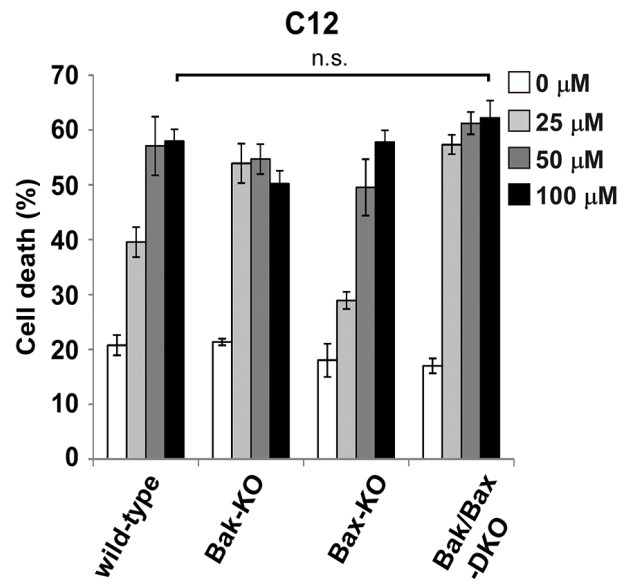

C

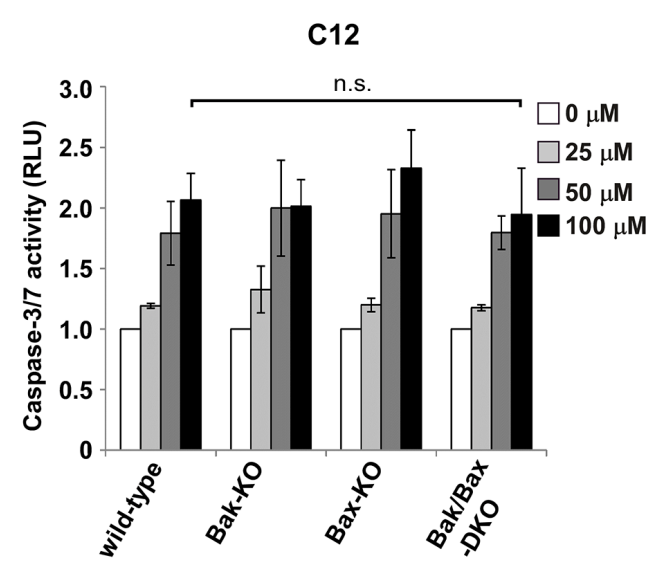

E

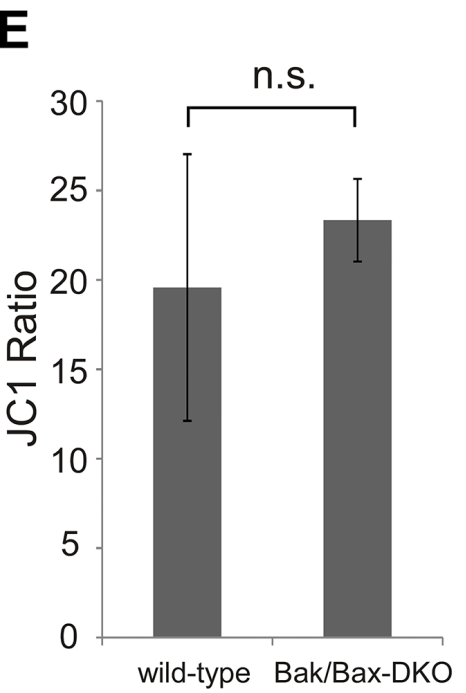

Figure 4: C12-induced tumor cell apoptosis is independent of Bak and Bax. (A) Bak and Bax expression in the indicated HCT116 cells was examined by western blot. (B-C) C12 induced similar levels of cell death (B) and caspase-3/7 activation (C) among WT, Bak-KO, Bax-KO and Bak/Bax-DKO HCT116 cells after 24 hours treatment. (D) The mitochondrial potential of WT and Bak/Bax-DKO HCT116 cells loaded with JC1 was determined by fluorescent microscopy upon the treatment with $50 \mu \mathrm{M} \mathrm{C12}$ and $5 \mu \mathrm{M}$ FCCP. Representative results are shown. (E) Summary of the data shown in (D). All data are presented as mean \pm standard deviation of three different experiments. ns, no significant. 
A

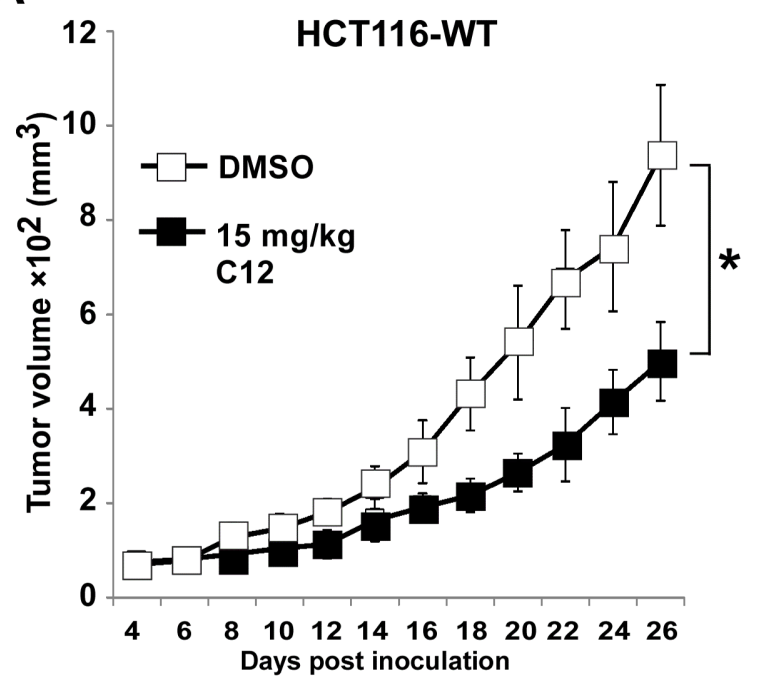

C
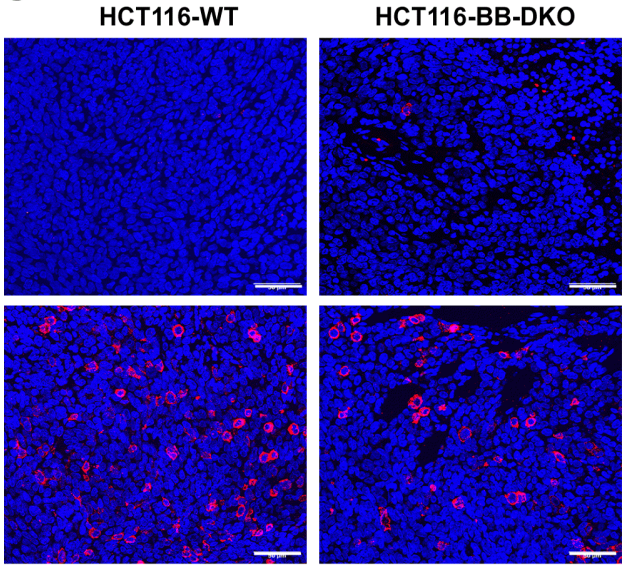

activated caspase 3

E

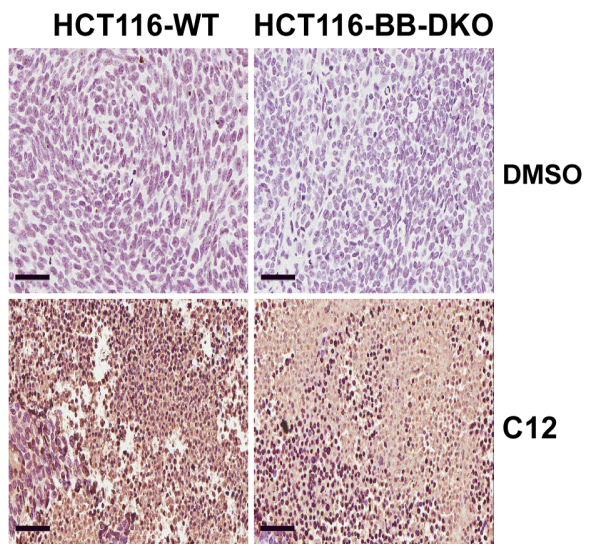

B

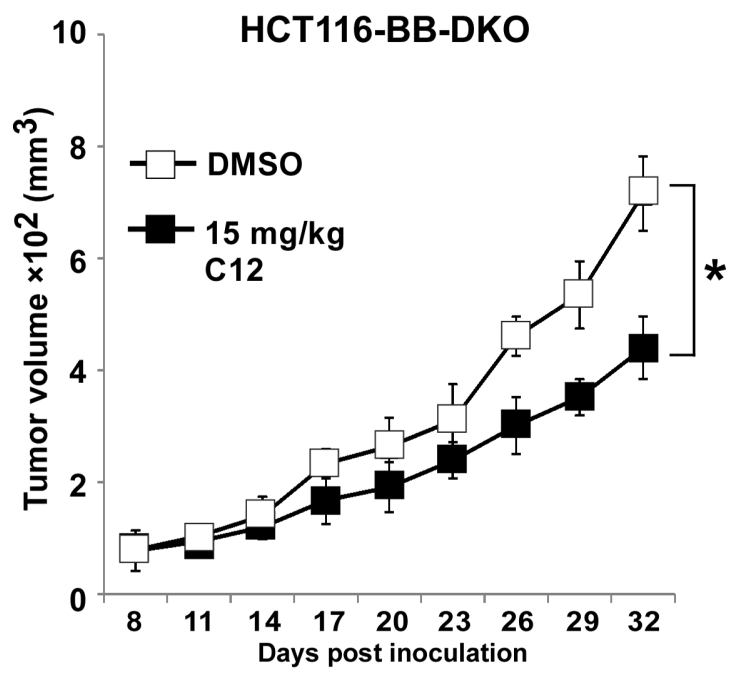

D

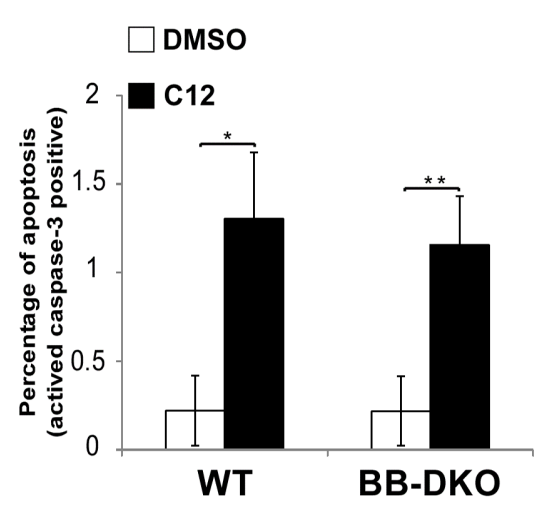

$\mathbf{F}$

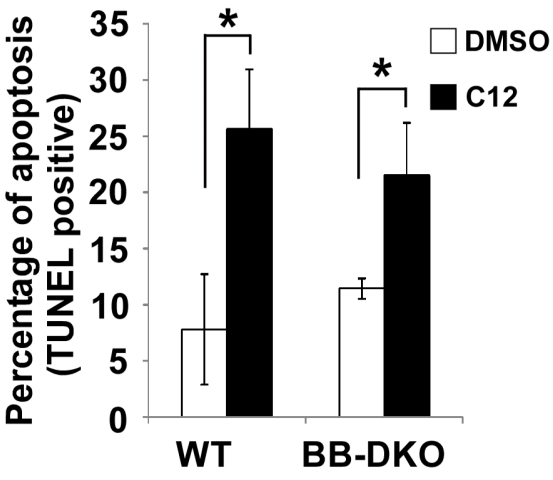

Figure 5: C12 inhibits xenografted tumor growth independent of Bak and Bax. (A-B) Growth of HCT116-WT tumors (A) and HCT116-Bak/Bax-DKO tumors (B) in athymic nude mice treated with vehicle control or C12 (15 mg/kg/day). Data are mean \pm standard deviation of tumor volumes of 8 animals in each group. (C) Apoptotic cells in tumor sections were detected by immunofluorescence staining of activated caspase-3. Representative images of tumor sections from DMSO- and C12-treated mice are shown. Scale bar, $50 \mu \mathrm{m}$. (D) The percentage of activated caspase-3 shown in (C) were quantified. Data are mean \pm standard deviation of three independent tumor sections. Asterisk indicates $P<0.05\left(^{*}\right)$ or $P<0.01$ (**) by student's unpaired $t$ test (E) Typical TUNEL labeling images of tumor sections from vehicle control- and C12-treated mice are shown. Scale bar, $60 \mu \mathrm{m}$. (F) The percentage of TUNEL-positive cells in tumors of $\mathrm{C} 12$-treated mice is higher than that of control mice. All data are mean \pm standard deviation of three independent tumor sections. Asterisk indicates $P<0.05\left(^{*}\right)$ by student's unpaired $t$ test. 
A

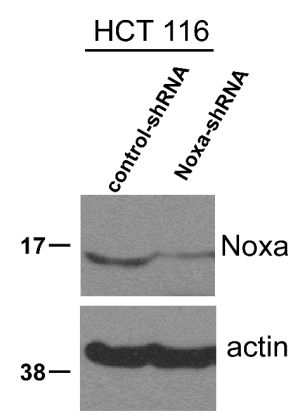

B

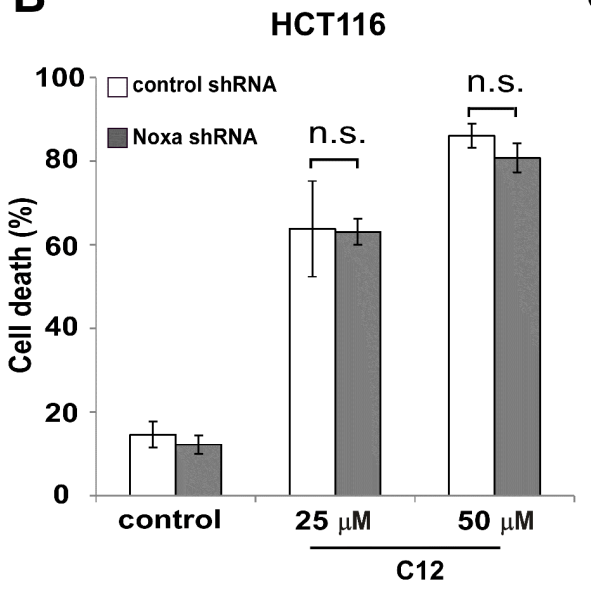

C

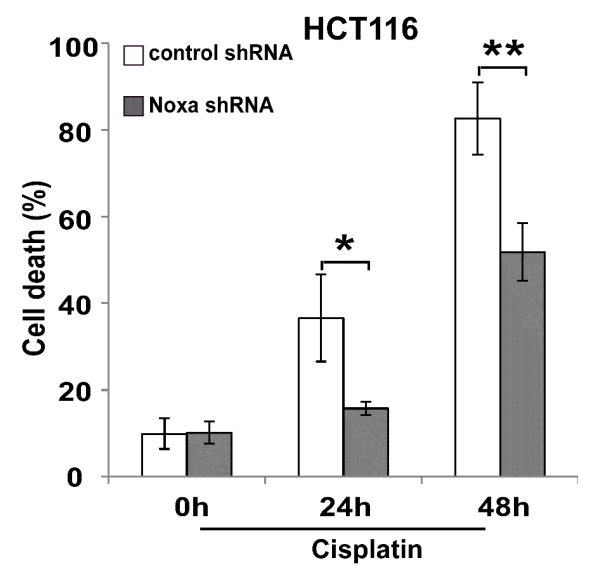

D HCT116

E
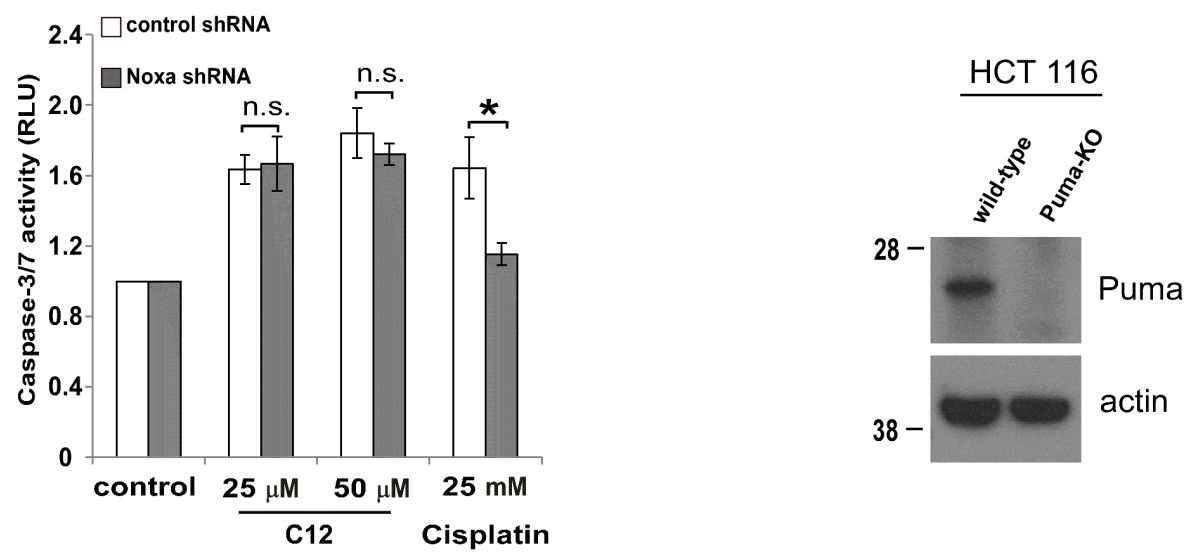

F

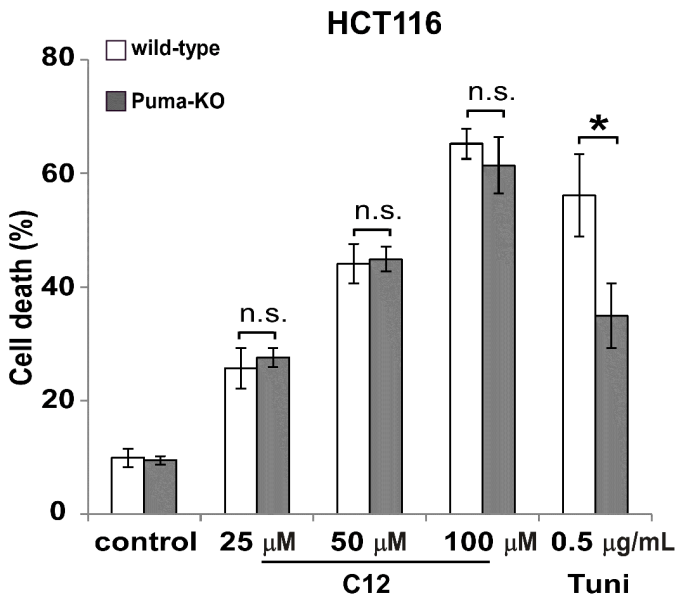

G

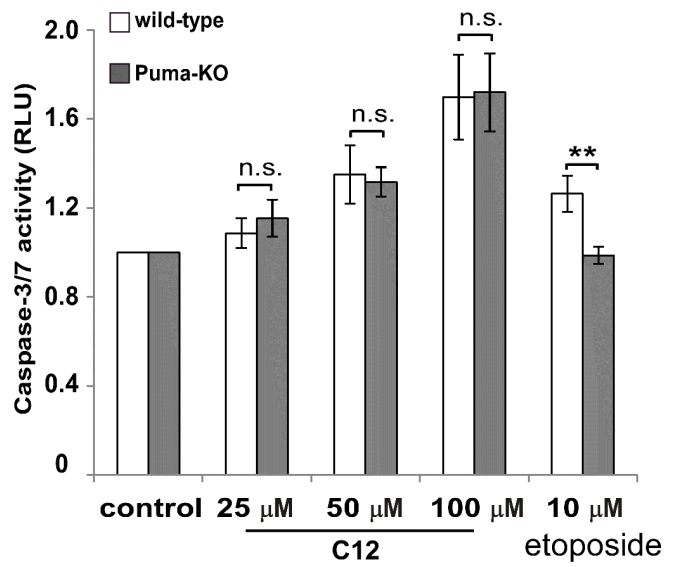

Figure 6: C12-induced tumor cell apoptosis is independent of BH-3 only proteins Noxa and Puma. (A) Noxa expression was stably reduced in HCT116 cells by shRNA. (B) Following 24 hours treatment of C12, similar levels of cell death were detected in HCT116 cells expressing Noxa shRNA and their control counterparts. (C) Less apoptosis was detected in HCT116 cells with reduced Noxa expression upon treatment of cisplatin $(50 \mu \mathrm{M})$. (D) Caspase-3/7activities were measured after 24 hour-incubation of C12 or cisplatin in the indicated HCT116 cells. (E) Puma expression in the indicated HCT116 cells was examined by western blot. (F) Cell death was measured after 24 hour-incubation of $\mathrm{C} 12$ or tunicamycin in Puma-deficient HCT116 cells or wild-type cells. (G) Caspase-3/7 activities were examined 24 hours after $\mathrm{C} 12$ or etoposide exposure. All data are presented as mean \pm standard deviation of three different experiments. Asterisk indicates $P<0.05(*)$ or $P<0.01(* *)$ by student's unpaired $t$ test. ns, no significant. 
in tumor cells. PON2 expression was stably reduced in human NSCLC cell lines A549 and NCI-H1299 using shRNA (Figure 8A and 8G). Upon treatment with $\mathrm{C} 12$, less cell death and caspase-3/7 activation were observed in A549 and NCI-H1299 cells lacking PON2 expression (Figure 8B-8D, 8H and 8J). In contrast, more cell death and caspase-3/7 activation were detected in PON2deficient cells in response to the common apoptotic stimuli actinomycin D and tunicamycin (Figure 8B, 8D and $8 \mathrm{I}-8 \mathrm{~J}$ ), suggesting that $\mathrm{PON} 2 / \mathrm{C} 12$ interaction induces a novel form of apoptosis distinct from that evoked by classical apoptotic stimuli. Importantly, C12 inhibited the growth of vector control A549 tumors but not the A549 tumors with reduced PON2 (Figure 8E-8F), further indicating that PON2 is vital for $\mathrm{C} 12$ cytotoxicity in vivo. In addition, similar levels of reduction in cell death and caspase-3/7 activation were observed in HCT116-WT and HCT116-Bak/Bax-DKO cells lacking PON2 expression (Supplementary Figure 9), demonstrating that Bak and Bax are not involved in PON2-mediated $\mathrm{C} 12$ cytotoxicity.

Previous studies indicate that PON2 reduces cellular oxidative damage and influences redox signaling and subsequent apoptotic pathways [23, 39, 40]. We investigated whether $\mathrm{C} 12$ modulated the antioxidant activities of PON2.

A

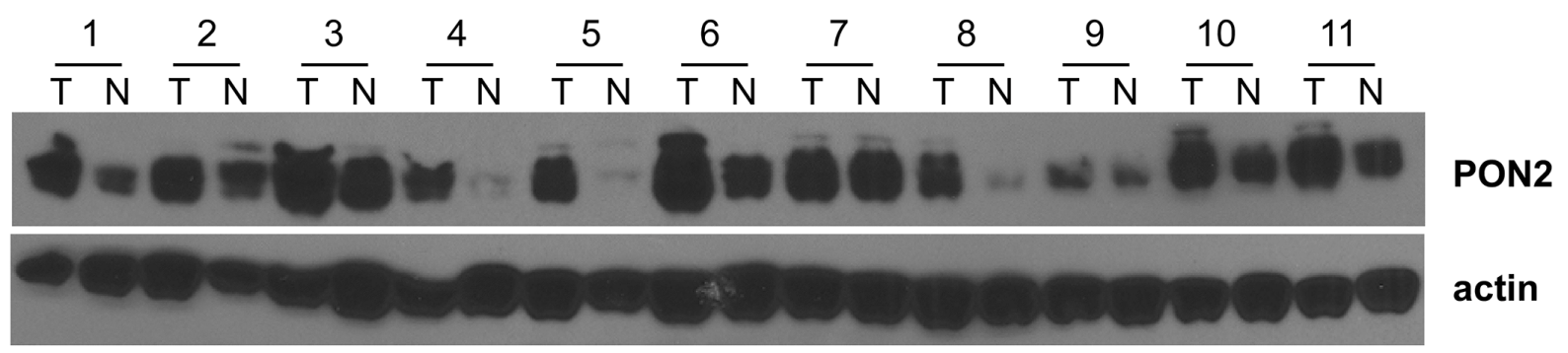

B

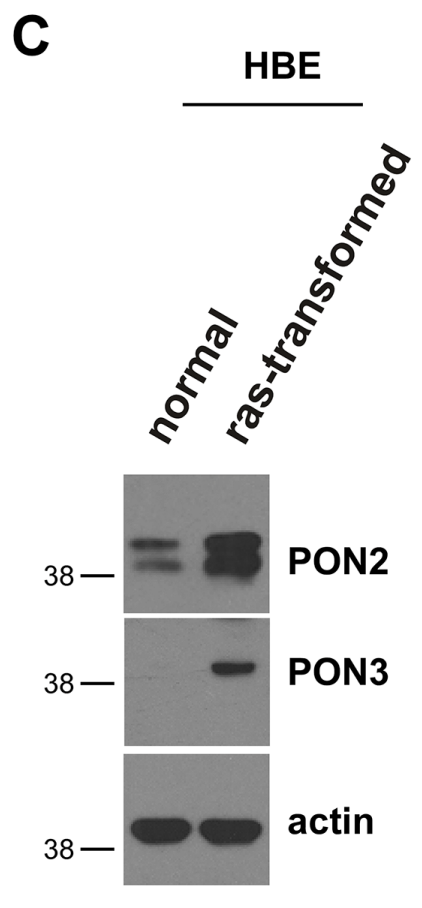

Figure 7: PON2 expression is enhanced in human lung tumor tissues and oncogenically transformed HBE cells. (A) Expression of PON2 in NSCLC tissue specimens and corresponding adjacent normal tissues from 11 patients were evaluated by western blot. Samples 1-4, 6, 8, 9, 11 were from adenocarcinoma patients, whereas samples 5, 7, 10 were from squamous cell carcinoma patients. T, tumor; N, normal. (B) The intensities of bands in (A) were quantified using ImageJ software (NIH). To normalize loading variation, the relative levels of PON2 were calculated by dividing the PON2 value into the corresponding value for actin. The data were shown as a ratio of PON2 levels in a tumor tissue sample versus its corresponding normal tissue, and the value bigger than 1 indicates that PON2 expression is increased in tumor tissues. Differential expression of PON2 in tumor versus normal tissues is significant with the value of "P" smaller than 0.01 as calculated by student's paired $t$ test. (C) The expression of PON2 and PON3 in primary HBE cells and their transformed counterparts was determined by western blot. 

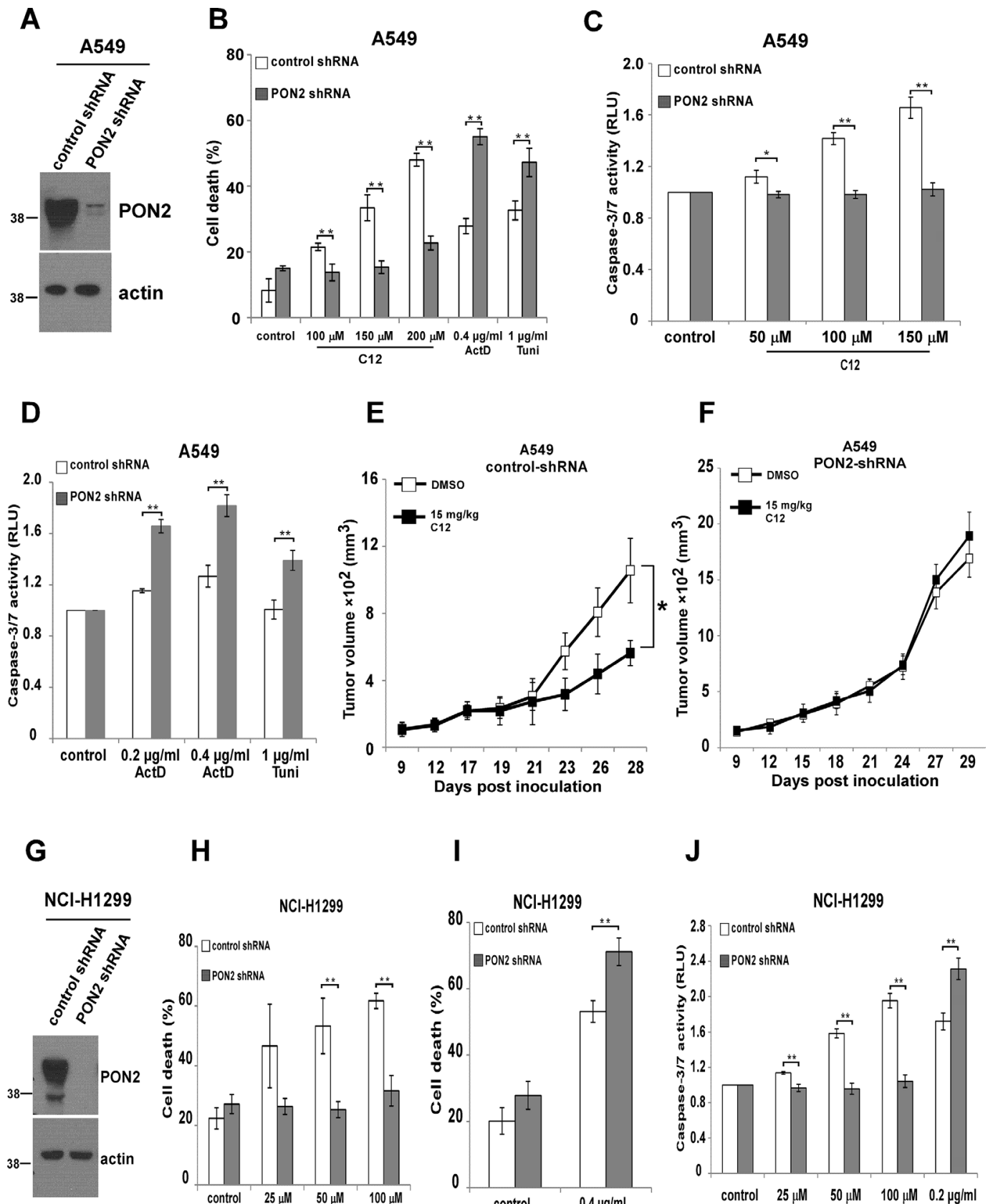

\section{H}

\section{I}
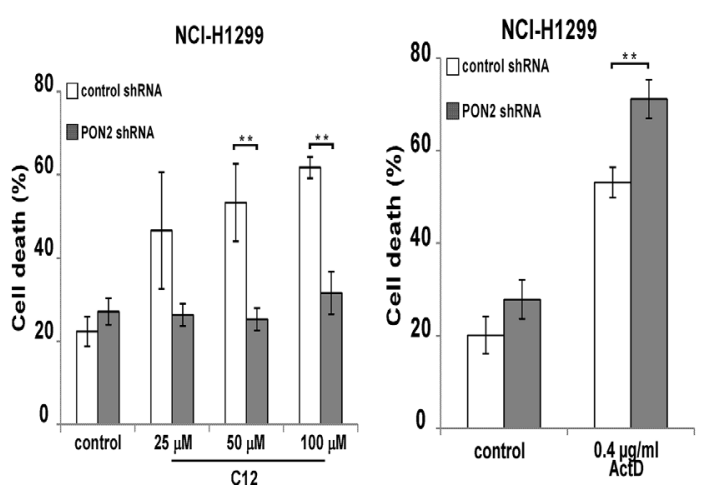

$\mathbf{J}$

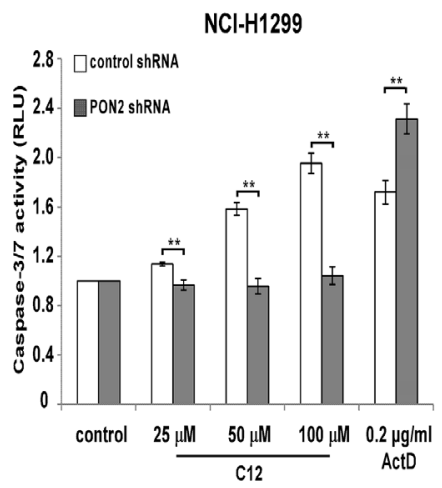

Figure 8: PON2 is required in C12's cytotoxicity on tumor cells and inhibitory effects on tumor growth. (A) PON2 expression in A549 cells was stably reduced by shRNA. The expression levels of PON2 were determined by western blot. (B) C12 induced less apoptosis in A549 cells with reduced PON2 expression than in control vector cells, which is opposite to the effects of actinomycin D or tunicamycin. Cell death was assessed after 32 hour incubation. (C) Upon treatment with different doses of C12 for 32 hours, less caspase-3/7 activation was detected in cells with reduced PON2 expression than control vector cells. (D) Actinomycin D or tunicamycin induced more caspase-3/7 activation in A549 cells with higher PON2 expression following 48 hour treatment. (E-F) Growth of A549-vector tumors $(\mathbf{E})$ and A549 tumors with reduced PON2 expression $(\mathbf{F})$ in athymic nude mice treated with vehicle control or C12 $(15 \mathrm{mg} / \mathrm{kg} / \mathrm{day})$. Data are mean \pm standard deviation of tumor volumes of 7 animals in each group. Asterisks indicate $P$ values of $<0.05(*)$ by student's unpaired $t$ test. (G) Stable reduction of PON2 expression in NCI-H1299 cells was evaluated by western blot. (H) C12 induced less cell death in NCI-H1299 cells with reduced PON2 following 24 hour treatment. (I) More cell death was detected in NCI-H1299 cells with lower PON2 expression following 24 hour exposure of actinomycin D. (J) Less apoptosis was detected in NCI-H1299 cells with reduced PON2 expression than control vector cells induced by $\mathrm{C} 12$, which is opposite to the effect of actinomycin D. Cell death was assessed after 24 hour incubation. All data shown are mean \pm standard deviation of three independent experiments performed in triplicate. Asterisks indicate $P$ values of $<0.05(*)$ or $<0.01(* *)$ by student's unpaired $t$ test. 
Consistent with earlier findings, reducing PON2 expression increased intracellular reactive oxygen species (ROS) levels in A549 and NCI-H1299 cells (Supplementary Figure 10). However, $\mathrm{C} 12$ failed to influence ROS production regardless of PON2 expression levels, indicating that the interaction between $\mathrm{C} 12$ and PON2 does not modulate the antioxidant activities of PON2.

\section{PON3 expression recovers $\mathrm{C} 12$ cytotoxicity in PON2-deficient tumor cells}

PON2 is known to function as a lactonase to cleave C12 [21, 41, 42]. Therefore, we reasoned that PON2 lactonase activity might be essential for $\mathrm{C} 12$ cytotoxicity on tumor cells. Since PON3 possesses overlapping enzymatic activities with PON2 to cleave C12 [43], we investigated whether PON3 could functionally compensate for the loss of PON2 and re-sensitize tumor cells to C12. To this purpose, the expression of human or murine PON3 was stably increased in PON2-deficient A549 and NCI-H1299 cells using retroviral infection. Western blot analysis showed that human PON3 and murine PON3 expression was significantly increased (Figure 9A and 9D). Overexpression of human or murine PON3 restored the sensitivity of PON2-deficient cells to C12, as measured by the levels of cell death and caspase-3/7 activation (Figure 9B-9C and 9E-9F). These data further validate the role of PON lactonase activity in $\mathrm{C} 12$-initiated apoptotic signaling in tumor cells.

\section{DISCUSSION}

Despite growing evidence that the bacterial quorum-sensing molecule $\mathrm{C} 12$ induces apoptosis in various types of human tumor cells [5-8], the relevance of $\mathrm{C} 12$ cytotoxicity to tumor growth in animals was unknown. Importantly, knowledge about the mechanism of C12-evoked tumor cell apoptosis has been limited. Here, we present the evidence that $\mathrm{C} 12$ preferentially triggers transformed cell apoptosis in vitro and inhibits transplanted tumor growth in vivo as a single agent independent of both anti- and pro-apoptotic Bcl-2 proteins. Furthermore, selective cytotoxicity of $\mathrm{C} 12$ on lung tumor cells and its inhibitory effects on tumor growth are likely related to upregulated PON2 expression in tumor cells.

Many neoplastic cells show an increased ratio of anti-apoptotic to pro-apoptotic Bcl-2 proteins, which enables them to survive even under the conditions that would normally initiate apoptotic signaling [9, 44]. An emerging strategy for cancer therapy is to overcome the resistance to apoptosis caused by aberrant Bcl-2 signaling in tumor cells [45-47]. Recently, several small molecules triggering apoptosis independent of either proor anti-apoptotic Bcl-2 proteins have been identified as potential anti-tumor drugs. Among them, the pentacyclic triterpenoid betulinic acid induces Bak/Bax-independent
MOMP and subsequent apoptosis [48]. Unlike C12, cytotoxic effects of betulinic acid are influenced by Bcl-2 overexpression and it is ineffective against epithelial tumors. Similarly, Bak/Bax is also nonessential in apoptotic signaling induced by chelerythrine [49], mitochondrial Kv1.3 channels inhibitors [50] or titanium dioxide $\left(\mathrm{TiO}_{2}\right)$ [51]. The polyphenolic compound gossypol evokes Bak/Bax-independent apoptosis and inhibits Bcl-2-overexpressing tumor growth [52]. Furthermore, Bcl-2 expression fails to influence human tumor cell apoptosis induced by the antibiotic agent Tetrocarcin-A or protein complex HAMLET $[16,17]$. Compared with those molecules, C12 is the first small molecule compound, to the best of our knowledge, inducing human tumor cell apoptosis in vitro as well as blocking tumor growth in vivo independent of both pro- and anti-apoptotic Bcl-2 proteins.

The apoptosis cascade induced by $\mathrm{C} 12$ in tumor cells is unique, evident by its rapid pro-apoptotic effects, such as depolarizing mitochondrial membrane potential within minutes (Figures 2 and 4), releasing cytochrome c into the cytosol within three hours (Supplementary Figures 6 and 8) and maximally activating caspases within four hours (Figure 1). These distinctive pro-apoptotic features of $\mathrm{C} 12$ have not been observed in any other apoptosis paradigms of cancer cells, which might be attributed to the ability of $\mathrm{C} 12$ or its derivatives generated in tumor cells to directly permeabilize mitochondria (within minutes) without the involvement of pro- and anti-apoptotic Bcl-2 proteins.

This study also shows that endogenous PON2 is essential for $\mathrm{C} 12$ 's cytotoxicity in human lung tumor cells and inhibitory effects on tumor growth (Figures 8-9), consistent with our previous observation of PON2 overexpression in nontransformed fibroblasts and HEK293T cells [25]. The ability of PON3 to restore the sensitivity of PON2-deficient tumor cells to C12 suggests that overlapping enzymatic activities of PON2 and PON3 mediate $\mathrm{C} 12$ killing activities. In addition, overexpressing wild-type but not lactonase-deficient PON2 in HEK293T cells sensitizes them to $\mathrm{C} 12$ [25]. These observations raise the possibility that a secondary, cytotoxic metabolite(s) of $\mathrm{C} 12$ generated by PON2 or PON3 is a more potent apoptosis inducer, which could be a carboxylic acid cleavage product of $\mathrm{C} 12$ or a molecule generated from its reaction with other molecules (e.g. phosphorylation). Future studies are warranted to identify such C12 metabolite(s).

It has been reported that lung tumor cell lines are resistant to conventional therapeutic drugs partially due to enhanced expression of PON2, which is thought to be associated with anti-oxidant activities of PON2 $[23,24]$. Our data also show that PON2 expression is enhanced in lung cancer tissues from NSCLC patients and human bronchia/tracheal epithelial cells transformed by an oncogenic Ras allele (Figure 7). Moreover, C12's ability to kill NSCLC tumor cells in vitro and block tumor 
A

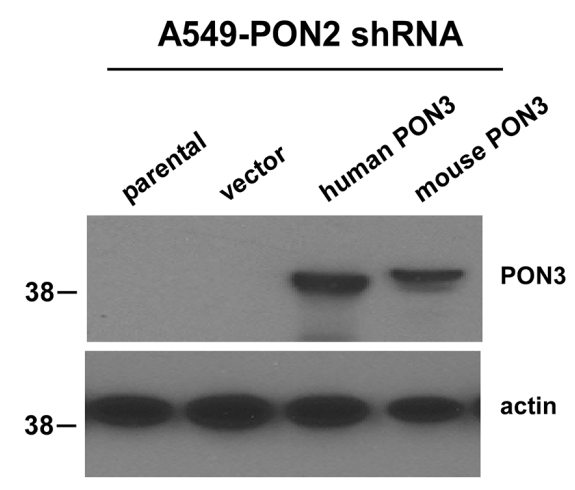

C

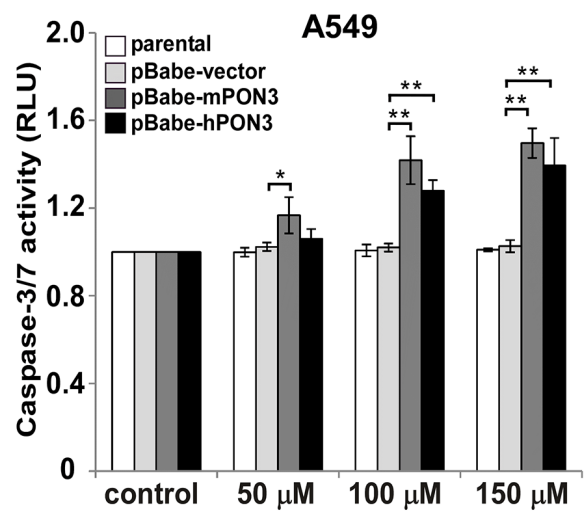

$\mathbf{E}$

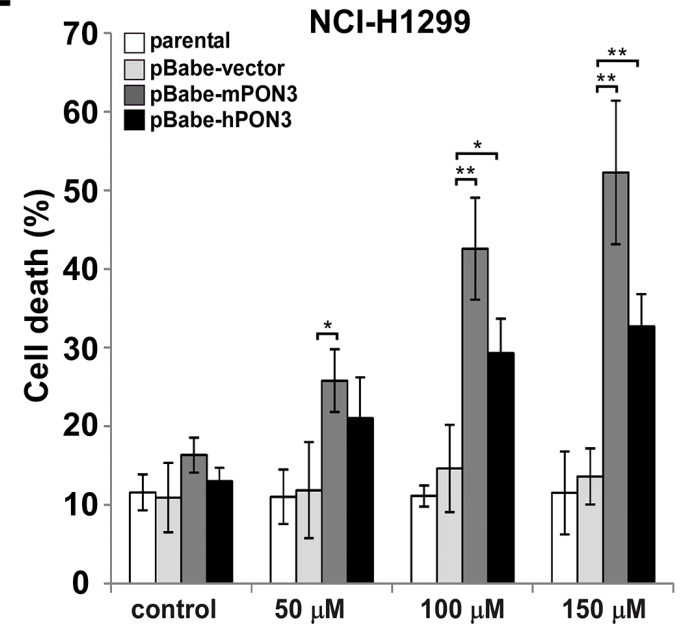

B

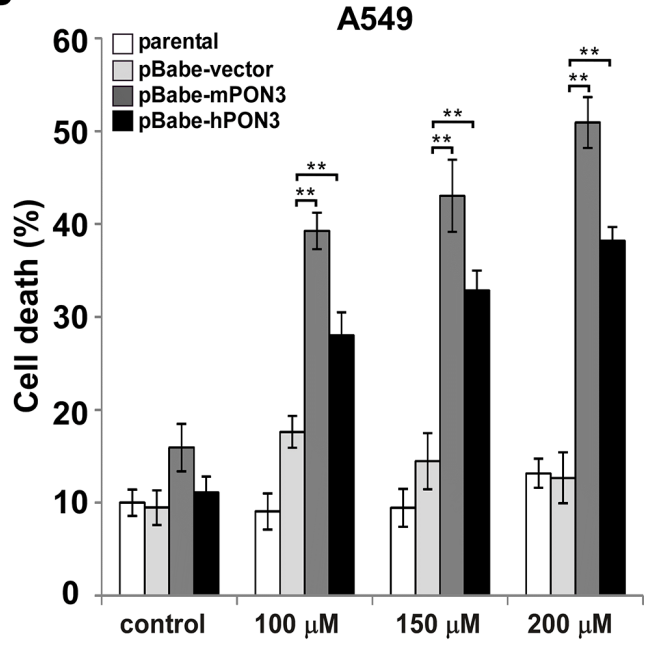

NCI-H1299-PON2 shRNA

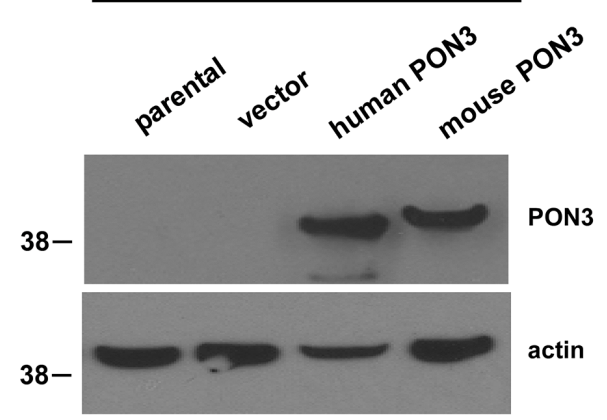

$\mathbf{F}$

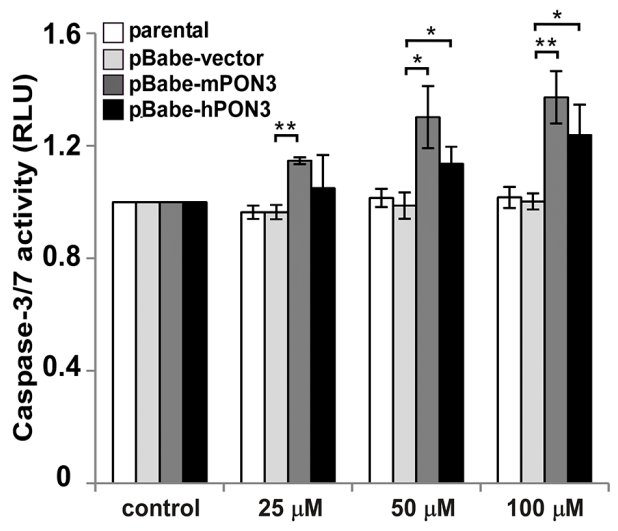

Figure 9: PON3 sensitizes tumor cells with reduced PON2 expression to C12. (A) Human or murine PON3 cDNA was stably overexpressed in A549 cells with reduced PON2 expression by retroviral infection. Expression levels of PON3 were determined by western blot. (B-C) After treating with different doses of C12 for 24 hours, more cell death (B) and caspase-3/7 activation (C) were detected in PON2-knockdown A549 cells with increased mouse and human PON3 expression comparing to vector control and parental cells. (D) Stable overexpression of human or murine PON3 in PON2-knockdown NCI-H1299 cells was examined by western blot. (E-F) C12 induced more cell death (E) and caspase-3/7 activation (F) in PON2-knockdown NCI-H1299 cells expressing mouse and human PON3 after 24 hours treatment. All data shown are mean \pm standard deviation of three independent experiments performed in triplicate. Asterisks indicate $P$ values of $<0.05(*)$ or $<0.01(* *)$ by student's unpaired $t$ test. 
growth in vivo is mediated through PON2 (Figure 8). These results indicate that the inhibitory effects of $\mathrm{C} 12$ on lung tumor growth in both normal and immunodeficient nude mice (Figures 3 and 5) could be attributed to PON2 overexpression in tumors. Thus, it is conceivable that $\mathrm{C} 12$ or compounds derived from $\mathrm{C} 12$ could trigger rapid and $\mathrm{Bcl}-2$ protein-independent apoptosis in lung tumors that are resistant to traditional chemotherapeutic drugs, whereas normal tissues are spared due to their lower PON2 expression.

As Pseudomonas aeruginosa produces $\mathrm{C} 12$ to control virulence factors, $\mathrm{C} 12$ alone could potentially promote infections, particularly in immune compromised patients [20]. Published information about the safety of $\mathrm{C} 12$ in vivo is limited except that $\mathrm{C} 12$ exerts acute influence in immune responses in mice. For instance, C12 reduces innate immune responses acutely via disrupting TLR4-dependent NF-kB signaling in mice [53]. In a murine model of dermal inflammation, intradermal injection of C12-loaded micelles leads to local immune cell infiltration within 24 hours [54]. In our studies, administration of $\mathrm{C} 12$ for extended periods of time does not appear to cause significant toxicity to either normal or immunodeficient athymic nude mice (Supplementary Figure 2), suggesting that long-term side effects of administrating $\mathrm{C} 12$ on animals might be limited.

Overall, our study reveals that $\mathrm{C} 12$ inhibits tumor growth in animals as a single agent, through inducing a unique Bcl-2 protein-independent and PON2-mediated apoptotic cascade in tumors. Therefore, C12 is an ideal candidate of a lead compound for novel therapeutic agents for cancer.

\section{MATERIALS AND METHODS}

\section{Reagents}

N-(3-oxododecanoyl)-homoserine lactone (C12), polybrene and actinomycin D were purchased from Sigma (St. Louis, MO). Propidium iodide (PI), CM-H2DCFDA (5-(and-6)-chloromethyl-2',7'-dichlorodihydrofluorescein diacetate, acetyl ester), TMRE (tetramethylrhodamine, ethyl ester) and TOTO-3 were obtained from Invitrogen (Carlsbad, CA). Unless otherwise stated, all reagents were dissolved in dimethyl sulfoxide (DMSO). Dulbecco's Modified Eagle's Medium (DMEM), penicillin/ streptomycin, trypsin, and L-glutamine were obtained from Mediatech (Manassas, VA), and fetal bovine serum was purchased from Gemini (Broderick, CA). CaspaseGlo assay 3/7 kit was purchased from Promega (Madison, $\mathrm{WI}$ ). Antibodies (Abs) for western blot were anti- $\beta$-actin mAb (Sigma), anti-Bcl-2 mAb; anti-Bax pAb (Santa Cruz; Dallas, TX), anti-Bak pAb (Millipore; Billerica, MA), anti-PON2 pAb; anti-PON3 pAb; anti-Mcl-1 pAb (Abcam; Cambridge, MA), anti-Noxa pAb (Novus; Littleton, CO), anti-Puma pAb (ProSic; Poway, CA) peroxidase-conjugated goat anti-rabbit IgG (Thermo Fisher; Waltham, MA) and peroxidase-conjugated goat anti-mouse IgG (Thermo Fisher).

\section{Plasmids}

The retroviral expression vector pBABE-IRESmKate2 was generated by replacing EGFP cDNA in pBABE-IRES-EGFP with mKate2 cDNA. Human PON3 cDNA (Sino Biological; China) or murine PON3 cDNA (Origene; Rockville, MD) was cloned into pBABE-IRESmKate2 to generate pBABE-hPON3-IRES-mKate2 or pBABE-mPON3-IRES-mKate2. pBABE-hBcl-2-IRESEGFP was generated by cloning human Bcl-2 cDNA into pBABE-IRES-EGFP. pMIG-hMcl-1-IRES-EGFP and pMIG-hBcl- $\mathrm{x}_{\mathrm{L}}$-IRES-EGFP was a gift from Dr. Levi Beverly (University of Louisville). The plasmid identities were validated by sequencing. Lentiviral human PON2 shRNA plasmid was purchased from Santa Cruz.

\section{Retrovirus and lentivirus production and cell culture}

Retrovirus and lentivirus were generated as described previously [55]. HCT116 cells expressing different levels of Bak and Bax were obtained from Dr. Richard Youle (National Institutes of Health). HCT116 cells stably expressing Noxa shRNA or the control luciferase shRNA were described previously [37]. Puma-deficient HCT116 cells were acquired from Dr. Bert Vogelstein (John Hopkins University). NSCLC cell line A549 cells were obtained from ATCC, which were produced from adenocarcinomic alveolar basal epithelial cells of a lung cancer patient [56]. NCI-H1299 cells were also acquired from ATCC. A549 cells expressing Mcl-1 shRNA or control scramble shRNA were described previously [31]. A549 cells overexpressing $\mathrm{Bcl}-2, \mathrm{Bcl}-\mathrm{x}_{\mathrm{L}}$ or $\mathrm{Mcl}-1$ were produced by retroviral infection as described previously [55]. To generate NCI-H1299 or A549 cells with reduced PON2 expression or vector control, we infected cells using respective lentiviral supernatants with $10 \mu \mathrm{g} / \mathrm{ml}$ polybrene. Stable cell lines were obtained by culturing cells in the medium containing $1.5 \mathrm{mg} / \mathrm{ml}$ puromycin. To express PON3 in NCI-H1299 or A549 cells with reduced PON2 expression, corresponding cells were infected with the retroviral supernatants containing $10 \mu \mathrm{g} / \mathrm{ml}$ of polybrene. NHBE cells were purchased from Lonza (Walkersville, MD). hT/LT/Ras HBE cells were obtained from Professor Barrett Rollins (Harvard Medical School). Lewis Lung Carcinoma cells, NCI-H1299 and A549 cells were cultured as described previously [55]. NHBE and $\mathrm{hT} / \mathrm{LT} / \mathrm{Ras}$ cells were grown in BEGM supplemented with SingleQuots (LONZA). HCT116 cells were grown as described previously [57]. Cells were all cultured in a $5 \% \mathrm{CO}_{2}$ humidified incubator at $37^{\circ} \mathrm{C}$. 


\section{Cell death analysis and Chou-Talalay synergism assay}

Cell viability of NCI-H1299 or A549 re-expressing PON3 cells was measured by $\mathrm{TOTO}^{\circledR}-3$ Iodide using flow cytometry (FACSCalibur) as described previously [51]. Cell viability in other studies was determined by propidium iodide exclusion using flow cytometry as described previously [55]. The synergistic effect of C12 and ABT-737 on cell viability was evaluated by Chou-Talalay median dose effect assay. $\mathrm{IC}_{50}$ of $\mathrm{C} 12$ and ABT-737 on NCI-H1299 or A549 was first determined. Various combinations of $\mathrm{C} 12$ and ABT-737 at a constant ratio above or below their $\mathrm{IC}_{50}$ values were added to cells. Following incubation for the indicated time, cell viability was evaluated and $\mathrm{Fa}$ (fractional activity) was determined as the ratio between the cell death levels of drug-treated cells and those of untreated control cells. Combination index (CI) was calculated by the CompuSyn software (Biosoft; Cambridge, UK).

\section{Caspase-3/7 activity and TUNEL labeling}

Caspase-3/7 activities were measured using a Caspase-Glo assay kit (Promega; Madison, WI) as described previously [58]. The proluminescent substrate containing the amino acid sequence Asp-Glu-Val-Asp (DEVD) is cleaved by activated caspase-3/7, leading to the release of a luciferase substrate (aminoluciferin) and the generation of luminescent signal. Data were presented as relative luminescent units (RLU) which were normalized to the corresponding values of control cells as an indicator of caspase-3/7 activities. TUNEL labeling was carried out by the Pathology Research Services Laboratory at University of Washington. The slides were scanned by a ScanScope CS digital slide scanner (Aperio; Vista, CA) and analyzed by ImageJ software (NIH) as described previously [46].

\section{Measuring $\Delta \psi_{\text {mito }}$ using imaging microscopy}

Cells were incubated with $10 \mu \mathrm{M} \Delta \psi_{\text {mito }}$ probe JC1 in growth media for 10 minutes at room temperature followed by three washes with Ringer's solution. Dye-loaded cells were mounted onto a chamber on the stage of a Nikon Diaphot inverted microscope with a Fluor $20 \mathrm{x}$ objective (0.75 NA) at room temperature. Treatments were made by diluting stock solutions into Ringer's solution at the indicated concentrations. Fluorescence imaging measurements of $\Delta \psi_{\text {mito }}$ were performed as reported previously $[25,34]$. Briefly, a charge coupled device camera collected JC-1 emission images using filter wheels (Lambda-10, Sutter Instruments; Novato, CA). Images were corrected for background (region without cells). Quantitative data are reported as JC1 fluorescence ratios normalized to minimal $\mathrm{JC} 1$ ratios obtained at the start of the experiment and maximal JC1 ratios obtained after $5 \mu \mathrm{M}$ FCCP treatment: Normalized JC1 Ratio = (Ratio at a given time - minimal Ratio) / (maximal ratio minimal Ratio) $* 100 \%$. Normalized JC1 ratios at plateau (before addition of FCCP) from different experiments have been averaged for summary charts.

\section{Mitochondrial morphology}

To image mitochondrial morphology and membrane potential using confocal microscopy, cells were transfected with mitochondrial matrix-targeted GFP plasmid (Clontech; Madison, WI) using an Amaxa nucleofector device (Lonza; Allendale, NJ), seeded onto $35 \mathrm{~mm}$ glass coverslips and placed in a tissue culture incubator. After 16-24 hours coverslips were mounted in a recording chamber positioned on the stage of an inverted microscope (IX71; Olympus America Inc., Center Valley, PA). Cells were visualized using a PlanApo 60x, 1.42 NA oil immersion objective and confocal time series images acquired using a VT-Infinity 3 (VisiTech International; Sunderland, UK). The chamber was perfused with Hank's Balanced Salt Solution containing $20 \mathrm{nM}$ mitochondrial membrane potential probe tetramethylrhodamine, ethyl ester (TMRE) at room temperature. After a 15 minute equilibration period, GFP and TMRE were alternately excited using the 488 and $568 \mathrm{~nm}$ lines respectively of a Krypon-Argon laser. The emitted fluorescence was filtered using a dual bandpass filter set (VisiTech International) and collected and using HCImage software (Hamamatsu Corporation; Sewickley, PA). Mitochondrial morphology was analyzed using ImageJ to determine the mean area/ perimeter ratio and inverse circularity as the measurement of interconnectivity and elongation respectively, as described previously [59].

\section{Immunofluorescence microscopy}

For immunofluorescence staining of A549 and HCT 116 cells, cells plated 24 hours earlier were incubated for 3 hours with either vehicle (DMSO) or $50 \mu \mathrm{M} \mathrm{C} 12$ in Ringer's solution. The immunofluorescence staining of cytochrome c was carried out as described previously [55]. Images were captured using a Nikon Eclipse Ti confocal microscope with a 40x CFI Plan Fluor objective (NA 0.6). To minimize variability, the same microscope settings were used for all experiments.

For immunofluorescence staining of tumor sections, tumor sections $(5 \mu \mathrm{m})$ were treated with antigen retrieval procedure by boiling in $10 \%$ Triton $\mathrm{x}-100$, then slowly cooled down at room temperature. After incubating with the blocking buffer ( $1 \times$ PBS, $0.2 \%$ Triton X-100, $5 \%$ goat serum), the slides were incubated with antibodies against activated caspase-3 (Cell signaling) overnight at $4^{\circ} \mathrm{C}$. Following three 10 -minute washes, slides were incubated with goat anti-rabbit IgG (Alexafluor-568, 
Invitrogen) for 1 hour. The fluorescence was visualized by confocal microscopy using a 40x CFI Plan Fluor objective (NA 0.6) and was analyzed using ImageJ software (NIH) as described previously [60].

\section{In vivo animal studies}

For C12 toxicity studies, DMSO or C12 $(25 \mathrm{mg} /$ $\mathrm{kg} /$ day) was administered intraperitoneally each day in 8 week-old C57BL/6 mice or in 6 week-old athymic nude mice. All organs were collected and weighted at sacrifice.

For transplanted tumors in C57BL/6 mice, eightweek old C57BL/6 female mice (Jackson Laboratories; Bar Harbor, ME) were inoculated subcutaneously (s.c.) with $1 \times 10^{6}$ Lewis Lung Carcinoma cells on the right flank. Tumors were measured daily with dull edged Vernier calipers $\left(\mathrm{V}=\mathrm{L} \times \mathrm{W}^{2}{ }^{2}\right)$. After tumor size reached around $100 \mathrm{~mm}^{3}$, animals with size-matched tumors were divided into control group and $\mathrm{C} 12$ group. DMSO or $\mathrm{C} 12$ was administered intraperitoneally each day. At the end of the experiments, tumors were excised for apoptosis evaluation. For the study of transplanted human tumors, female athymic nude mice (5-7 weeks) were purchased from Harlan Laboratories (Indianapolis, IN). Wild-type HCT116 cells and Bak/Bax DKO HCT116 cells $\left(3.0 \times 10^{7} / \mathrm{ml}\right)$, wild-type A549 cells and Bcl-2overexpressing A549 cells $\left(3.0 \times 10^{7} / \mathrm{ml}\right)$, A549-controlshRNA cells and A549-PON2-shRNA cells $\left(3.0 \times 10^{7} / \mathrm{ml}\right)$ were resuspended and mixed 1:1 ( $\mathrm{vol} / \mathrm{vol})$ with Matrigel (BD Biosciences), then $0.1 \mathrm{ml}$ mixture of cells and Matrigel was injected s.c. on the right flank of mice. All animals with size-matched tumors were divided into two groups (control and $\mathrm{C} 12$ ) when the tumor size reached around $100 \mathrm{~mm}^{3}$. For HCT116 and Bak/Bax DKO HCT116 tumors, DMSO or C12 was administered intraperitoneally each day. DMSO or etoposide $(40 \mathrm{mg} / \mathrm{kg} /$ day) was administered intraperitoneally once every other day. For wild-type A549 tumors, animals were treated with $\mathrm{C} 12$ for 6 times/week. For Bcl-2 over-expressing A549 cells tumors, DMSO or C12 was administered with C12 each day. For A549-control-shRNA and A549-PON2shRNA tumors, DMSO or C12 was administered twice every three days. At the end of the experiments, tumors were excised for apoptosis evaluation.

\section{Lung tumor tissues from patients}

Tumor tissues along with corresponding adjacent normal tissues from non small cell lung carcinoma (NSCLC) patients were acquired from the James Graham Brown Cancer Center Bio-Repository at University of Louisville following an approved IRB protocol. Frozen tissue samples were resuspended in tissue protein extraction reagent (Thermo Fisher) supplemented with protease inhibitors (Complete, Roche; Indianapolis, IN) and phosphatase inhibitors (PhosSTOP, Roche). Following homogenization and centrifugation, protein concentration was determined by BCA assay (Thermo Fisher). Thirty micrograms of total protein was electrophoresed in $4-12 \%$ Bis/Tris gels (Bio-Rad; Hercules, CA). PON2 was detected by western blot as described previously [46].

\section{ROS measurement}

A549 or NCI-H1299 cells were cultured in 96-well white-walled plates $\left(7.5 \times 10^{3}\right.$ per well $)$ for 24 hours. Cells were subsequently treated with DMSO or $100 \mu \mathrm{M}$ CM-H2DCFDA in growth medium for 1 hour at $37^{\circ} \mathrm{C}$. Growth medium was then removed and cells were washed twice with Ringer's Buffer. DMSO or $100 \mu \mathrm{M} \mathrm{C12}$ in Ringer's Buffer was added to cells. The fluorescence signal $(\mathrm{Ex} / \mathrm{Em}=492 \mathrm{~nm} / 520 \mathrm{~nm})$ was measured kinetically at $37^{\circ} \mathrm{C}$ using the Gemini EM microplate spectrofluormeter (Molecular Devices; Sunnyvale, CA). Data was plotted as relative fluorescence units (RFUs) versus time and the slope was determined (RFU/min) as an indicator of intracellular ROS level.

\section{Statistical analysis}

Results are presented as mean \pm standard deviation of at least three independent experiments. Statistical analysis was performed using Student's two tail $t$-test. A $p$ value $<0.05$ was considered significant.

\section{ACKNOWLEDGMENTS}

We are grateful to Dr. John Eaton (University of Louisville) for critical reading of the paper, Dr. Richard Youle (National Institutes of Health) for providing HCT116 cells expressing different levels of Bak and Bax, Dr. Bert Vogelstein (John Hopkins University) for providing Puma-deficient HCT116 cells, and Dr. Andrei Smolenkov at the James Graham Brown Cancer Center Bio-Repository (University of Louisville) for providing lung tumor tissues from patients. This work was supported by National Institutes of Health grants CA106599, CA175003, GM106386, and RR018733 and a University of Louisville Research Initiation Grant (CL) and grants from National Institutes of Health PN2-EY-018241 and Cystic Fibrosis Research, Inc. New Horizons (TM). This work was also funded by CAS Pioneer Hundred Talents Program (GZ) and National Natural Science Foundation of China Grant 81300769 (HL).

\section{CONFLICTS OF INTEREST}

There is no actual, potential, or perceived conflicts of interest to disclose.

\section{Authors' contributions}

Guoping Zhao, Christian Schwarzer, Carl White, Terry Machen and Chi Li designed research. Guoping 
Zhao, Aaron Neely, Christian Schwarzer, Huayi Lu, Aaron Whitt, Nicole Stivers, Joseph Burlison, and Carl White performed research. Guoping Zhao, Aaron Neely, Christian Schwarzer, Huayi Lu, Aaron Whitt, Nicole Stivers, Joseph Burlison, Carl White, Terry Machen and Chi Li analyzed data. Guoping Zhao and Chi Li wrote the paper.

\section{REFERENCES}

1. Miller MB, Bassler BL. Quorum sensing in bacteria. Annu Rev Microbiol. 2001; 55:165-199.

2. Shiner EK, Rumbaugh KP, Williams SC. Interkingdom signaling: Deciphering the language of acyl homoserine lactones. Fems Microbiol Rev. 2005; 29:935-947.

3. Hughes DT, Sperandio V. Inter-kingdom signalling: communication between bacteria and their hosts. Nat Rev Microbiol. 2008; 6:111-120.

4. Kravchenko VV, Kaufmann GF. Bacterial inhibition of inflammatory responses via TLR-independent mechanisms. Cell Microbiol. 2013; 15:527-536.

5. Li L, Hooi D, Chhabra SR, Pritchard D, Shaw PE. Bacterial $\mathrm{N}$-acylhomoserine lactone-induced apoptosis in breast carcinoma cells correlated with down-modulation of STAT3. Oncogene. 2004; 23:4894-4902.

6. Kumar AS, Bryan JN, Kumar SR. Bacterial Quorum Sensing Molecule N-3-Oxo-Dodecanoyl-L-Homoserine Lactone Causes Direct Cytotoxicity and Reduced Cell Motility in Human Pancreatic Carcinoma Cells. PLoS One. 2014; 9:e106480.

7. Dolnick R, Wu Q, Angelino NJ, Stephanie LV, Chow KC, Sufrin JR, Dolnick BJ. Enhancement of 5-fluorouracil sensitivity by an rTS signaling mimic in $\mathrm{H} 630$ colon cancer cells. Cancer Res. 2005; 65:5917-5924.

8. Oliver CM, Schaefer AL, Greenberg EP, Sufrin JR. Microwave Synthesis and Evaluation of Phenacylhomoserine Lactones as Anticancer Compounds that Minimally Activate Quorum Sensing Pathways in Pseudomonas aeruginosa. J Med Chem. 2009; 52:1569-1575.

9. Evan GI, Vousden KH. Proliferation, cell cycle and apoptosis in cancer. Nature. 2001; 411:342-348.

10. Yip KW, Reed JC. Bcl-2 family proteins and cancer. Oncogene. 2008; 27:6398-6406.

11. Youle RJ, Strasser A. The BCL-2 protein family: opposing activities that mediate cell death. Nat Rev Mol Cell Bio. 2008; 9:47-59.

12. Williams MM, Cook RS. Bcl-2 family proteins in breast development and cancer: could Mcl-1 targeting overcome therapeutic resistance? Oncotarget. 2015; 6:3519-3530. doi: 10.18632/oncotarget.2792.

13. Ertel F, Nguyen M, Roulston A, Shore GC. Programming cancer cells for high expression levels of Mcl1. EMBO reports. 2013; 14:328-336.

14. Sturm I, Petrowsky H, Volz R, Lorenz M, Radetzki S, Hillebrand T, Wolff G, Hauptmann S, Dorken B, Daniel PT.
Analysis of p53/BAX/p16(ink4a/CDKN2) in esophageal squamous cell carcinoma: High BAX and p16(nk4a/ CDKN2) identifies patients with good prognosis. J Clin Oncol. 2001; 19:2272-2281.

15. Tai YT, Lee S. BAX protein expression and clinical outcome in epithelial ovarian cancer (vol 16, pg 2583, 1998). J Clin Oncol. 1998; 16:3211-3211.

16. Hallgren $\mathrm{O}$, Gustafsson L, Irjala H, Selivanova G, Orrenius S, Svanborg C. HAMLET triggers apoptosis but tumor cell death is independent of caspases, Bcl-2 and p53. Apoptosis. 2006; 11:221-233.

17. Anether G, Tinhofer I, Senfter M, Greil R. Tetrocarcin-Ainduced ER stress mediates apoptosis in B-CLL cells via a Bcl-2 —independent pathway. Blood. 2003; 101:4561-4568.

18. Yue $\mathrm{W}$, Zheng $\mathrm{X}$, Lin Y, Yang CS, Xu Q, Carpizo D, Huang H, DiPaola RS, Tan XL. Metformin combined with aspirin significantly inhibit pancreatic cancer cell growth in vitro and in vivo by suppressing anti-apoptotic proteins Mcl-1 and Bcl-2. Oncotarget. 2015; 6:21208-24. doi: 10.18632/oncotarget.4126.

19. Bar-Rogovsky H, Hugenmatter A, Tawfik DS. The evolutionary origins of detoxifying enzymes: the mammalian serum paraoxonases (PONs) relate to bacterial homoserine lactonases. J Biol Chem. 2013; 288:23914-23927.

20. Harel M, Aharoni A, Gaidukov L, Brumshtein B, Khersonsky O, Meged R, Dvir H, Ravelli RB, McCarthy A, Toker L, Silman I, Sussman JL, Tawfik DS. Structure and evolution of the serum paraoxonase family of detoxifying and anti-atherosclerotic enzymes. Nature structural \& molecular biology. 2004; 11:412-419.

21. Stoltz DA, Ozer EA, Ng CJ, Yu JM, Reddy ST, Lusis AJ, Bourquard N, Parsek MR, Zabner J, Shih DM. Paraoxonase-2 deficiency enhances Pseudomonas aeruginosa quorum sensing in murine tracheal epithelia. Am J Physiol-Lung C. 2007; 292:L852-L860.

22. Schweikert EM, Devarajan A, Witte I, Wilgenbus P, Amort J, Forstermann U, Shabazian A, Grijalva V, Shih DM, Farias-Eisner R, Teiber JF, Reddy ST, Horke ST. PON3 is upregulated in cancer tissues and protects against mitochondrial superoxide-mediated cell death. Cell Death Differ. 2012; 19:1549-1560.

23. Witte I, Altenhofer S, Wilgenbus P, Amort J, Clement AM, Pautz A, Li H, Forstermann U, Horke S. Beyond reduction of atherosclerosis: PON2 provides apoptosis resistance and stabilizes tumor cells. Cell Death Dis. 2011; 2:e112.

24. Horke S, Witte I, Forstermann U. Protectors and traitors: opposing functions of human paraoxonases in atherosclerosis and cancer. N-S Arch Pharmacol. 2012; 385:39-39.

25. Schwarzer $\mathrm{C}, \mathrm{Fu} \mathrm{Z}$, Morita T, Whitt AG, Neely AM, Li C, Machen TE. Paraoxonase 2 Serves a Proapopotic Function in Mouse and Human Cells in Response to the Pseudomonas aeruginosa Quorum-Sensing Molecule N-(3oxododecanoyl)-Homoserine Lactone. J Biol Chem. 2015; 290:7247-58. 
26. Chai HB, Hazawa M, Shirai N, Igarashi J, Takahashi K, Hosokawa Y, Suga H, Kashiwakura I. Functional properties of synthetic N-acyl-L-homoserine lactone analogs of quorum-sensing gram-negative bacteria on the growth of human oral squamous carcinoma cells. Invest New Drug. 2012; 30:157-163.

27. Soejima K, Fang WZ, Rollins BJ. DNA methyltransferase $3 \mathrm{~b}$ contributes to oncogenic transformation induced by SV40T antigen and activated Ras. Oncogene. 2003; 22:4723-4733.

28. Serrano M, Lin AW, McCurrach ME, Beach D, Lowe $\mathrm{SW}$. Oncogenic ras provokes premature cell senescence associated with accumulation of p53 and p16INK4a. Cell. 1997; 88:593-602.

29. Hahn WC, Counter CM, Lundberg AS, Beijersbergen RL, Brooks MW, Weinberg RA. Creation of human tumour cells with defined genetic elements. Nature. 1999; 400:464-468.

30. Kelly PN, Strasser A. The role of Bcl-2 and its pro-survival relatives in tumourigenesis and cancer therapy. Cell Death Differ. 2011; 18:1414-1424.

31. Huang H, Shah K, Bradbury NA, Li C, White C. Mcl-1 promotes lung cancer cell migration by directly interacting with VDAC to increase mitochondrial $\mathrm{Ca} 2+$ uptake and reactive oxygen species generation. Cell Death Dis. 2014; 5:e1482.

32. Newmeyer DD, Ferguson-Miller S. Mitochondria: releasing power for life and unleashing the machineries of death. Cell. 2003; 112:481-490.

33. Vaux DL, Cory S, Adams JM. Bcl-2 gene promotes haemopoietic cell survival and cooperates with c-myc to immortalize pre-B cells. Nature. 1988; 335:440-442.

34. Schwarzer C, Fu Z, Shuai S, Babbar S, Zhao GP, Li C, Machen TE. Pseudomonas aeruginosa homoserine lactone triggers apoptosis and $\mathrm{Bak} / \mathrm{Bax}$-independent release of mitochondrial cytochrome $\mathrm{C}$ in fibroblasts. Cell Microbiol. 2014; 16:1094-1104.

35. Renault TT, Chipuk JE. Death upon a Kiss: Mitochondrial Outer Membrane Composition and Organelle Communication Govern Sensitivity to BAK/BAX-Dependent Apoptosis. Chem Biol. 2014; 21:114-123.

36. Strasser A. The role of $\mathrm{BH} 3$-only proteins in the immune system. Nat Rev Immunol. 2005; 5:189-200.

37. Eno CO, Zhao G, Venkatanarayan A, Wang B, Flores ER, Li C. Noxa couples lysosomal membrane permeabilization and apoptosis during oxidative stress. Free Radic Biol Med. 2013; 65:26-37.

38. Yu J, Wang Z, Kinzler KW, Vogelstein B, Zhang L. PUMA mediates the apoptotic response to p53 in colorectal cancer cells. Proc Natl Acad Sci U S A. 2003; 100:1931-1936.

39. Altenhofer S, Witte I, Teiber JF, Wilgenbus P, Pautz A, Li H, Daiber A, Witan H, Clement AM, Forstermann U, Horke S. One enzyme, two functions: PON2 prevents mitochondrial superoxide formation and apoptosis independent from its lactonase activity. J Biol Chem. 2010; 285:24398-24403.

40. Ng CJ, Wadleigh DJ, Gangopadhyay A, Hama S, Grijalva VR, Navab M, Fogelman AM, Reddy ST.
Paraoxonase-2 is a ubiquitously expressed protein with antioxidant properties and is capable of preventing cellmediated oxidative modification of low density lipoprotein. J Biol Chem. 2001; 276:44444-44449.

41. Draganov DI, Teiber JF, Speelman A, Osawa Y, Sunahara R, $\mathrm{La} \mathrm{Du}$ BN. Human paraoxonases (PON1, PON2, and PON3) are lactonases with overlapping and distinct substrate specificities. J Lipid Res. 2005; 46:1239-1247.

42. Chun CK, Ozer EA, Welsh MJ, Zabner J, Greenberg EP. Inactivation of a Pseudomonas aeruginosa quorum-sensing signal by human airway epithelia. P Natl Acad Sci USA. 2004; 101:3587-3590.

43. Witte I, Foerstermann U, Devarajan A, Reddy ST, Horke S. Protectors or Traitors: The Roles of PON2 and PON3 in Atherosclerosis and Cancer. Journal of lipids. 2012; 2012:342806.

44. Straten $\mathrm{P}$, Andersen MH. The anti-apoptotic members of the Bcl-2 family are attractive tumor-associated antigens. Oncotarget. 2010; 1:239-245. doi: 10.18632/oncotarget.134.

45. Vogler M, Dinsdale D, Dyer MJS, Cohen GM. Bcl-2 inhibitors: small molecules with a big impact on cancer therapy. Cell Death Differ. 2009; 16:360-367.

46. Zhao GP, Zhu YL, Eno CO, Liu YL, DeLeeuw L, Burlison JA, Chaires JB, Trent JO, Li C. Activation of the Proapoptotic Bcl-2 Protein Bax by a Small Molecule Induces Tumor Cell Apoptosis. Mol Cell Biol. 2014; 34:1198-1207.

47. Besbes S, Mirshahi M, Pocard M, Billard C. New dimension in therapeutic targeting of BCL-2 family proteins. Oncotarget. 2015; 6:12862-12871. doi: 10.18632/oncotarget.3868.

48. Mullauer FB, Kessler JH, Medema JP. Betulinic acid induces cytochrome c release and apoptosis in a Bax/ Bak-independent, permeability transition pore dependent fashion. Apoptosis. 2009; 14:191-202.

49. Wan KF, Chan SL, Sukumaran SK, Lee MC, Yu VC. Chelerythrine induces apoptosis through a Bax/Bak-independent mitochondrial mechanism. J Biol Chem. 2008; 283:8423-8433.

50. Leanza L, Henry B, Sassi N, Zoratti M, Chandy KG, Gulbins E, Szabo I. Inhibitors of mitochondrial Kv1.3 channels induce Bax/Bak-independent death of cancer cells. EMBO molecular medicine. 2012; 4:577-593.

51. Zhu YL, Eaton JW, Li C. Titanium Dioxide (TiO2) Nanoparticles Preferentially Induce Cell Death in Transformed Cells in a Bak/Bax-Independent Fashion. PLoS One. 2012; 7:e50607.

52. Lei X, Chen Y, Du G, Yu W, Wang X, Qu H, Xia B, He H, Mao J, Zong W, Liao X, Mehrpour M, Hao X, Chen Q. Gossypol induces Bax/Bak-independent activation of apoptosis and cytochrome c release via a conformational change in Bcl-2. FASEB journal. 2006; 20:2147-2149.

53. Kravchenko VV, Kaufmann GF, Mathison JC, Scott DA, Katz AZ, Grauer DC, Lehmann M, Meijler MM, Janda KD, Ulevitch RJ. Modulation of gene expression via disruption of NF-kappaB signaling by a bacterial small molecule. Science. 2008; 321:259-263. 
54. Valentine CD, Zhang H, Phuan PW, Nguyen J, Verkman AS, Haggie PM. Small molecule screen yields inhibitors of Pseudomonas homoserine lactone-induced host responses. Cell Microbiol. 2014; 16:1-14.

55. Zhao G, Lu H, Li C. Pro-apoptotic activities of PDI and PDIA3: a role of Bcl-2 protein Bak. J Biol Chem. 2015; 290:8949-63.

56. Giard DJ, Aaronson SA, Todaro GJ, Arnstein P, Kersey JH, Dosik H, Parks WP. In vitro cultivation of human tumors: establishment of cell lines derived from a series of solid tumors. J Natl Cancer Inst. 1973; 51:1417-1423.

57. Wang C, Youle RJ. Predominant requirement of Bax for apoptosis in HCT116 cells is determined by Mcl-1's inhibitory effect on Bak. Oncogene. 2012; 31:3177-3189.
58. Zhao GP, Wang J, Wang XF, Chen SP, Zhao Y, Gu F, Xu A, Wu LJ. Mutagenicity of PFOA in Mammalian Cells: Role of Mitochondria-Dependent Reactive Oxygen Species. Environ Sci Technol. 2011; 45:1638-1644.

59. Dagda RK, Cherra SJ, Kulich SM, Tandon A, Park D, Chu CT. Loss of PINK1 Function Promotes Mitophagy through Effects on Oxidative Stress and Mitochondrial Fission. J Biol Chem. 2009; 284:13843-13855.

60. Lu HY, Lu QX, Zheng YJ, Li QT. Notch signaling promotes the corneal epithelium wound healing. Mol Vis. 2012; 18:403-411. 